\section{Research Square}

Preprints are preliminary reports that have not undergone peer review.

They should not be considered conclusive, used to inform clinical practice, or referenced by the media as validated information.

\title{
Transcriptome analysis reveals potential mechanisms and pathways underlying embryonic development with respect to muscle growth and egg production in slow and fast growing chickens
}

\author{
M. Kanakachari \\ ICAR-Directorate of Poultry Research \\ R. Ashwini \\ ICAR-Directorate of Poultry Research \\ R. N. Chatterjee \\ ICAR-Directorate of Poultry Research \\ T. K Bhattacharya ( $\sim$ bhattacharyatk@gmail.com) \\ ICAR-Directorate of Poultry Research
}

\section{Research Article}

Keywords: Fast and slow growth chicken, 7th and 18th-day embryo tissues, Microarray, Reference gene, Quantitative real-time PCR.

Posted Date: March 29th, 2021

DOI: https://doi.org/10.21203/rs.3.rs-346155/v1

License: () (1) This work is licensed under a Creative Commons Attribution 4.0 International License. Read Full License 


\section{Abstract}

Background: Chicken is one of the important meat sources throughout the globe. Muscle development and egg production are important genetic traits in commercially raising chickens. However, not much information is available in the fast and slow growth of chicken to determine the expression of genes involved in muscle development and egg production in embryo initiation and developmental stages. This study was designed to investigate why improved Aseel (PD4) growing slowly compared with the control broiler (CB), microarray was conducted with the $7^{\text {th }}$-day embryo and $18^{\text {th }}$-day thigh muscle of improved Aseel (PD4) and control broiler (CL), respectively.

Results: In the differential transcripts screening, all the transcripts obtained by microarray of slow and fast growth groups were screened by fold change $\geq 1$ and false discovery rate $(F D R)<0.05$. In total, 19022 transcripts were differentially expressed between the $7^{\text {th }}$-day embryo and $18^{\text {th }}$-day thigh muscle of improved Aseel compared to the control broiler. Further analysis showed that a high number of transcripts are differentially regulated in the $7^{\text {th }}$-day improved Aseel embryo (15382) and fewer transcripts were differentially regulated (3640) in the $18^{\text {th }}$-day thigh muscle of improved Aseel compared to control broiler. In the $7^{\text {th }}$ and $18^{\text {th }}$-day improved Aseel embryo, 10127, 2102, 5255, and 1538 transcripts were up and down-regulated, respectively. The commonly up and downregulated transcripts are 545 and 381 between the $7^{\text {th }}$ and $18^{\text {th }}$-day of embryos. In this study, we have selected 18 Gallus gallus candidate reference genes from NCBI and total RNA was isolated from control broiler, improved Aseel embryo tissues, and studied their expression profiles by real-time quantitative PCR (qPCR). The best housekeeping gene was identified by using geNorm, NormFinder, BestKeeper, Delta CT, and RefFinder analytical software. The result showed that the TFRC gene is the most stable and further it is used for qPCR data normalization. Further, to validate the differentially expressed genes (DEGs) related to muscle growth, myostatin signaling and development, fatty acid metabolism genes in improved Aseel (PD4) and control broiler embryo tissues by qPCR.

Conclusion: Our study identified DEGs that regulate myostatin signaling and differentiation pathway, glycolysis and gluconeogenesis, fatty acid metabolism, Jak-STAT, mTOR, and TGF- $\beta$ signaling pathways, tryptophan metabolism, PI3K-Akt signaling pathways in improved Aseel. The results revealed that the gene expression architecture is present in the improved Aseel exhibiting embryo growth that will help to improve muscle development, differentiation, egg production, as well as protein synthesis in improved Aseel native chicken. Our findings may be used as a model for improving the growth in improved Aseel as well as optimizing the growth in the control broiler.

\section{Background}

Animal agriculture production is essential for supplying protein nutrition concerning the increasing global human population. Broiler chickens are genetically selected with highly improved production efficiency through rapid growth and high feed efficiency compared to improved Aseel native chicken birds. Therefore, understanding of mechanisms regulating rapid muscle growth and high feed efficiency between control broiler and improved Aseel may improve the qualities in improved Aseel animal production systems [1].

In high and low production efficiency breast muscle phenotype male pedigree broiler breeder chickens were used for global gene expression cDNA microarray study $[2,3,4]$. Also, RNAseq global gene expression studies have been performed with breast muscle and duodenal tissue in commercial broilers and low and high residual feed intake broilers, respectively $[5,6]$. The global gene expression studies mostly showed that production ability could also be related to different cellular mechanisms as well as mitochondrial oxidative stress, inflammatory response, protein degradation, stress responses, growth hormone signaling, cell cycle, apoptosis, and fatty acid transportation. A recent transcriptome study reported differentially expressed genes are enriched in myogenic growth and differentiation on the $6^{\text {th }}$ and $21^{\text {st }}$ days of breast muscles in modern pedigree broiler chicken compared with legacy chicken lines [7]. A transcriptome analysis was performed with pectoralis major muscles of slow and fast-growing chickens $(n=8)$ to understand the myopathies related structural changes and molecular pathways using an $8 \times 60 \mathrm{~K}$ Agilent chicken microarray and histological study. For fast-growing breast meat yield, functional analysis revealed the favoring metabolic shifts towards alternative catabolic pathways, oxidative stress, inflammatory, regeneration, fibrosis processes, cellular defense, and remodeling [8]. A transcriptome profiling analysis was performed in two chicken lines i.e. high (pHu+) and low (pHu-) using an Agilent custom chicken $8 \times 60 \mathrm{~K}$ microarray. Between two lines, 1436 differentially expressed (DE) genes were found and they are related to biological processes for muscle development and remodeling, carbohydrate, and energy metabolism [9]. A genome-wide association study (GWAS) was conducted for assessing body weight in an F2 chicken population and a microarray expression study was done with the liver of high and low-weight chickens. Also, identified miR-16 as a key regulator, it will suppress the chicken embryo cell proliferation and cellular growth. The mutated miR-16 by inserting 54 bp is showed a significant increase in body weight, bone size, and muscle mass [10]. The comparative transcriptome analysis of grouper fish muscle in hybrid and its parents showed up-regulation of genes related to glycolysis, calcium signaling, and troponin pathways led to enhance muscle growth in the hybrid grouper [11]. Insulin-like growth factor 1 (IGF1) and a cascade of intracellular components (protein kinase B, mTOR, GSK3 $\beta$, and FoxO) play a major role in the regulation of skeletal muscle growth during development and regeneration [12].

Muscle growth contains complex network combinations i.e. cell proliferation, differentiation, and metabolism [13]. In mammals, during the embryonic period, the total skeletal muscle fibre number is initiated and after birth, only muscle hypertrophy occurs $[14,15,16]$. In teleosts, hypertrophic and hyperplastic muscle growth can happen during the entire life simultaneously $[17,18]$. However, in chicken, the total skeletal muscle fibre number is initiated and fixed during the embryonic period $[19,20]$. In consequence, chicken muscle mass accounts for a better proportion of bodyweight and it is an excellent experimental model for studying fundamental growth regulatory mechanisms in vertebrates [21]. Therefore, for controlling muscle growth, understanding the mechanisms in chicken is necessary to optimize poultry. In America during the mid-19 ${ }^{\text {th }}$ century, dual-purpose both egg and meat chicken i.e. Barred Plymouth Rock (BPR) is a foundational or heritage breed of the modern commercial broilers was developed by crosses with Black Java, Black Cochin, and Dominique breed with alternating white and black bars of feather pigmentation $[22,23]$.

For egg production, multiple gene interactions in a variety of organs regulate energy metabolism, protein synthesis, and storage [24]. Previous genomics and transcriptomic reports identified genes associated with reproduction traits [25]. In ovaries, twenty-six differentially expressed genes (DEGs) were identified 
between pre-laying and egg-laying periods [26]. The twelve genes identified related to reproduction regulation pathways such as GnRH, G-protein coupled receptor, calcium-signaling pathways, biosynthesis of steroid hormones, oocyte meiosis, and progesterone-mediated oocyte maturation [27]. In chicken, nine transcripts related to high egg production were identified in the hypothalamus and pituitary gland [28]. Recently, a comparative transcriptome study was done between the hypothalamus and the pituitary gland in Chinese dagu chickens [29]. However, no studies reported how to regulates the genes in embryos for oogenesis and egg development in chickens.

In this present study, a microarray gene expression study was conducted with distinct different growth characteristics of embryo tissue ( $7^{\text {th }}$-day embryo and $18^{\text {th }}$-day thigh muscle) obtained from the control broiler (rapid growth and muscle development) and improved Aseel (slow growth and lower efficiency), respectively. Also, 18 housekeeping genes were tested in both breeds and identified TFRC as the best gene for qPCR data normalization. In this study, a comparison of global gene expression was done between improved Aseel and control broiler embryo tissue, which shows greater differences of differentially expressed genes may provide more ultimate perception into cellular regulatory mechanisms in muscle growth, egg production and feed efficiency.

\section{Methods}

\section{Animals}

The study was conducted in control broiler and PD-4 (improved Aseel) chicken lines maintained at the Institute farm, ICAR-Directorate of Poultry Research, Hyderabad, India (Fig. 1a). The improved Aseel (PD-4) has been developed from Indian native Aseel breed of chicken by imposing selection for body weights at 8 weeks of age for last 10 generations. The body weight of these birds at 8 weeks of age during S-10 generation was $551.0 \pm 3.60 \mathrm{~g}$. The control broiler birds are random bred broilers and there is no selection imposed in this population. The body weight of control broiler line at 6 weeks of age was $951.0 \pm 1.20 \mathrm{~g}$. The birds of both the population were maintained under intensive system of management. A total of 60 fertile eggs were kept for hatching (30 for each group) in the incubator (Global incubators, Hyderabad, India) at $100.3^{0} \mathrm{~F}$ temperature and $79.2^{0} \mathrm{~F}$ humidity. After the $7^{\text {th }}$ and $18^{\text {th }}$-day of incubation, eggs were harvested (15 for each group) and embryos were collected and stored at $-80^{\circ} \mathrm{C}$ up to total RNA isolation.

\section{Ethics Statement}

The control broiler and PD-4 chicken lines were maintained in the institute farm (ICAR-Directorate of Poultry Research, Hyderabad, India) and fertile eggs were collected for this experiment. The whole experiment including all the protocols was approved by the Institute Animal Ethics committee (IAEC) of ICARDirectorate of Poultry Research, Hyderabad, India. The study was carried out in compliance with the ARRIVE guidelines. All methods were carried out in accordance with relevant guidelines and regulations of IAEC and ARRIVE.

\section{RNA extraction and evaluation}

For RNA isolation complete embryo from $7^{\text {th }}$-day and thigh muscle from $18^{\text {th }}$-day embryo was used from control broiler and PD4 lines. The tissue of the samples collected from three independent embryos during each time point to isolate RNA and considered each replicate as one biological replicate during each period. Total RNA was isolated using Trizin RNA extraction reagent (GCC Biotech Pvt. Ltd. India) according to the manufacturer's protocol and RNA was purified by DNase treatment (DNase I solution, HIMEDIA, India) for removing trace amount of DNA. The purity and quantity were monitored on $1.2 \%$ denatured agarose gels and NanoDrop 1000 Spectrophotometer (Thermo Scientific, USA). Quality of total RNA was assessed by checking 200-300 ng of total RNA on an RNA Nano Chip using an Agilent Bioanalyzer 2100 (Agilent technologies, USA) according to the manufacturer's instructions.

\section{RNA Labelling, Amplification, and Hybridization}

The Agilent Quick Amp Kit (Part number: 5190-0442) was used for sample labeling. 500ng of total RNA was reverse transcribed using an oligodT primer tagged to a T7 promoter sequence and in the same reaction, CDNA thus obtained was converted to double-stranded cDNA. Labeled cRNA preparation and hybridization on GeneChip and scanning was done following Affymetrix protocols (http://www.affymetrix.com). In the in-vitro transcription step, the cDNA was converted to cRNA using the T7 RNA polymerase enzyme and Cy3 dye was added into the reaction mix and was incorporated into the newly synthesized strands, and obtained cRNA was cleaned up using Qiagen RNeasy columns (Qiagen, Cat No: 74106). The concentration and amount of dye incorporated were determined using NanoDrop 1000 Spectrophotometer (Thermo Scientific, USA). The QC passed samples for specific activity were taken for hybridization. $600 \mathrm{ng}$ of labeled cRNA was hybridized on the array using the Gene Expression Hybridization Kit (Part Number 5190-0404; Agilent technologies, USA) in Sure Hybridization Chambers (Agilent technologies, USA) at $65^{\circ} \mathrm{C}$ for 16 hours. Agilent Gene Expression wash buffers (Part No: 5188-5327) were used for washing the hybridized slides and then scanned on a G2505C scanner (Agilent Technologies, USA).

\section{Microarray Data Analysis}

After scanning DAT, CEL, CHP, XML, and JPEG image files were generated for each array with Feature Extraction Software (Version-10.7, Agilent Technologies, USA). The CEL files containing estimated probe intensity values were further analyzed with GeneSpring GX-11.0 software (Agilent Technologies, USA). Normalization of the data was done in GeneSpring GX using the $75^{\text {th }}$ percentile shift and this normalization takes each column in an experiment independently, and computes the percentile of the expression values for this array, across all spots, and fold change was calculated concerning specific control samples. Genes up and down-regulated showing one fold and above within the samples concerning the control sample were identified, and for the replicates student T-test p-value was calculated. The expression data obtained have been submitted to the Gene Expression Omnibus database (GEO, http://www.ncbi.nlm.nih.gov/geo) at U.S. National Center for Biotechnology Information with the accession numbers GSE62443-GSE62445.

\section{Hierarchical clustering analysis}


The differentially expressed genes between the $7^{\text {th }}$ and $18^{\text {th }}$-day of the embryo were subjected to hierarchical cluster analysis using the Cluster 3.0 program [30]. We imported the matrix with as many columns as stages and many rows as genes, where each cell contains the log2 transformed fold change value for the gene and individual into the Cluster 3.0 program, normalizing on rows. We applied both rows and columns in hierarchical clustering and exported the resulting dendrogram as an image file.

\section{Functional Characterization}

Functional annotation, classification, and annotation clustering of selected gene sets were carried out by DAVID Tools 6.7 using biological processes, molecular function gene ontology categories, and KEGG pathways [31, 32]. A threshold for significance of $\mathrm{P}<0.05$ was considered to choose the significant functional categories.

\section{Pathway analyses}

Ingenuity Pathway Analysis (IPA; Qiagen, Valencia, CA; http://www.ingenuity.com) software was used for functional annotation, canonical pathway analysis, upstream analysis, and network discovery. The chicken DEGs data sets functionalities are primarily based on mammalian biological mechanisms because IPA is based on bioinformatics in humans. We have attempted to draw possible conclusions based on avian-based literature but biomedical research biases the functional annotations towards human disease

\section{Selection of candidate reference genes}

A total of 24 candidate reference genes were chosen based on their previous use/study in chicken or other avian species and the sequences were downloaded from NCBI (https://www.ncbi.nlm.nih.gov/) and CDS (coding DNA sequence) region was identified by using ExPASy translation tool (https://web.expasy.org/translate/) (Table 1).

\section{Real-Time Quantitative PCR analysis}

Microarray expression data was validated using two-step Real-Time Quantitative PCR (qPCR) for specific confirmation of the differentially expressed genes. First-strand cDNA was synthesized from $2 \mu \mathrm{g}$ of total RNA using Thermo Scientific Verso cDNA Synthesis Kit (Thermo Scientific, USA). Gene specific qPCR primers were designed for 24 housekeeping genes and 83 DEGs using PrimerQuest software (http://eu.idtdna.com; Table S1; Table 2). The qPCR was performed using the BrightGreen 2X qPCR MasterMix-No Dye (Applied Biological Materials Inc., Canada) in Insta Q96 ${ }^{\text {TM }}$ Real-Time Machine (Himedia Laboratories, India) detection system. The PCR was performed under the following program; $5 \mathrm{~min}$ at $95^{\circ} \mathrm{C}$, followed by 40 cycles of amplification with $15 \mathrm{~s}$ of denaturation at $95^{\circ} \mathrm{C}, 60 \mathrm{~s}$ of annealing/extension at $60^{\circ} \mathrm{C}$. Three biological replicates were used. To check the specificity of the amplified products melt curve analysis was performed. The $2^{-\Delta \Delta C t}$ calculated the relative expression level of each gene, and Transferrin (TFRC; Accession No: X55348.1) from G. gallus was used as a housekeeping gene to normalize the amount of template cDNA added in each reaction.

\section{Statistical Analysis}

The stability level of the 18 candidate reference genes from $7^{\text {th }}$ and $18^{\text {th }}$ day embryos of control broiler and improved Aseel was determined by using five statistical algorithms geNorm, NormFinder, BestKeeper, Delta CT and RefFinder [33,34,35,36,37]. Comparison of mean expression values for qRT-PCR between the control broiler and PD4 improved Aseel groups were made using student's $t$-test and $P \leq 0.05$ were considered as statistically significant.

\section{Results And Discussion}

The understanding of the gene functions, rapid and reliable quantification of gene expression, currently quantitative real-time PCR (qPCR) is one of the most sensitive techniques widely used. In quantitative gene expression, normalization is a key factor for accuracy and reliability, for that endogenous reference gene were used. According to the MIQE guidelines, the selection of suitable reference genes may vary for different species, different varieties, experimental conditions, and tissues and have to be validated before gene expression study [38]. Previous and recent studies also described different expression patterns of reference genes and focused on the validation of reference genes applied on different avian tissues [39,40,41]. However, so far validation of genes for their stable expression pattern in different embryo tissues such as $7^{\text {th }}$ and $18^{\text {th }}$-day embryos of control broiler and improved Aseel was not performed.

\section{Source, selection, primer design, verification of candidate reference genes}

In the present study, to identify the suitable reference genes for $7^{\text {th }}$ and $18^{\text {th }}$-day embryos of control broiler and improved Aseel, 24 candidate reference genes with a wide range of biological functions were selected based on previous studies of various avian and non-avian species. They are 18SrRNA, ALB, B2MG, $\beta$ ACT, EEF1A1, GAPDH, GUSB, HMBS, HSP10, HSP70, L-LDBC, MRPS27, MRPS30, PGK2, PPP2CB, RPL5, RPL13, RPL14, RPL19, RPL23, SDHA, TBP, TFRC, and DNAJC24. The chicken orthologous genes were obtained from NCBI, CDS region was found and amplified with gene-specific primers (Table S1). For all the primer pairs, melting curve analysis was performed to confirm the specific amplification for each reference gene, which showed presence of single peak indicating specificity of the amplification of the genes.

\section{Expression stability and ranking of candidate reference genes}

Expression levels of all candidate reference genes were measured in the samples collected from $7^{\text {th }}$ and $18^{\text {th }}$-day embryos of the control broiler and improved Aseel. We observed that not all selected reference genes were expressing uniformly across different embryos of control broiler and improved Aseel (Fig. 3). Differential transcription abundance levels were observed among all 18 genes. The mean Ct values of the selected reference gene ranged from 12.34 to 28.27 
irrespective of different embryos. 18S rRNA and DNAJC24 genes showed the most (Ct=12.34) and the least (Ct=33.88) abundant transcripts respectively. Each reference gene had different expression ranges across all sample sets. The results show that the GUSB reference gene had the least variation of expression with mean Ct values ranging from 17.78 to 22.52 whereas the RPL5 gene showed a much higher expression variation with mean $\mathrm{Ct}$ values ranging from 13.07 to 32.89 across all sample sets (Fig. 3). It is important to note that there was a wide range of variation among selected reference genes, and it shows that not a single reference gene expresses constantly across the $7^{\text {th }}$ and $18^{\text {th }}$ day of embryos of control broiler and improved Aseel in the present study (Fig. 3 ). Therefore, it is of pivotal importance to choose the most reliable reference gene for expression profiling of gene/s in different embryos of control broiler and improved Aseel.

For accurate gene expression, to select the best and most reliable reference gene and rank all the candidate reference genes according to their stability value, the most commonly used statistical programs were used i.e. geNorm, NormFinder, BestKeeper, Delta CT, and RefFinder $[39,40,41,42,43,44,45,46,47,48]$. These algorithms showed some differences in the stability ranking of stable reference genes, which may be due to the differences in each statistical program (Table 1). It is important to rank the stabilities of 18 genes and to confirm the number of reference genes necessary for accurate gene expression profiling under embryo initiation and developmental stages. The variation among the reference genes determined by geNorm is stability measure ( $\mathrm{M}$ value) and pairwise comparison expression ratio and provides optima number of genes in a given experiment $[49,50]$. According to geNorm stability criteria, the most stable genes in the $7^{\text {th }}$ and $18^{\text {th }}$ embryos of the control broiler and improved Aseel were PGK2 (0.38) and TFRC (0.38). NormFinder measures the reference gene stability by overall expression variation and across samples variation to reduce sensitivity towards co-regulation $[49,51]$. According to NormFinder stability criteria, the most stable genes in the $7^{\text {th }}$ and $18^{\text {th }}$ embryos of the control broiler and improved Aseel were GAPDH (0.371) and TFRC (0.4). BestKeeper calculates the gene expression variation based on Ct values and also calculates the Pearson correlation coefficient by pairwise correlation analysis for all reference genes and found the stable genes. According to BestKeeper stability criteria, the most stable genes in the $7^{\text {th }}$ and $18^{\text {th }}$ embryos of the control broiler and improved Aseel were HSP70 (1.08) and PPP2CB (1.11). The Delta CT results supported geNorm and NormFinder results and it showed the best stable genes in $7^{\text {th }}$ and $18^{\text {th }}$ embryos of control broiler and improved Aseel i.e. TFRC (2.1) and PGK2 (2.13). RefFinder conclusive the calculations using the all above-mentioned algorithms and suggested the stable genes in $7^{\text {th }}$ and $18^{\text {th }}$ embryos of control broiler and improved Aseel i.e. TFRC (2.21) and PGK2 (2.85).

To overcome different software program limitations, the stability of candidate reference genes was determined based on the consensus ranking for gene expression normalization in $7^{\text {th }}$ and $18^{\text {th }}$-day embryos of control broiler and improved Aseel. Our study identified the most stable genes and indicated that, TFRC and PGK2 for $7^{\text {th }}$ and $18^{\text {th }}$-day embryos of control broiler and improved Aseel. Our observations further strengthen the necessity to analyze the stability of candidate reference genes as suitable references.

\section{Differentially expressed transcripts during embryo development stages}

To study the effect of muscle development, genome-wide expression analysis was carried out at muscle initiation ( $7^{\text {th }}$-day embryo) and muscle development $\left(18^{\text {th }}\right.$-day thigh muscle) stages (Fig. 1a, b). Labeled RNA was hybridized to Affymetrix GeneChip ${ }^{\text {TM }}$ Chicken Genome Array. After statistical data analysis, transcripts with FDR adjusted P-value $\leq 0.01$ and fold change $\geq 1$ were considered as significantly DETs (Fig. 1c). The complete list of the DETs in improved Aseel during embryo development stages as compared to their respective control broiler samples is presented in Supporting Document 1 \& 2 . In total 19,022 transcripts (16,252 unigenes) which accounted for approximately $58 \%$ of the total transcripts present on the GeneChip ${ }^{\mathrm{TM}}$ Chicken Genome Array were showed differential expression in improved Aseel at various stages analyzed. The maximum number of transcripts $(15,380,46.9 \%$ of total DETs) showed differential expression on the $7^{\text {th }}$ day of the embryo and the least number of transcripts $\left(3642,11.11 \%\right.$ of total DETs) showed differential expression on the $18^{\text {th }}$ day of the embryo. Commonly up-and down-regulated muscle responsive transcripts were identified among the embryo development stages to find out the degree of overlap (Fig. 1d, e). The maximum number of commonly up-regulated (9582) and down-regulated transcripts (4874) was observed in a $7^{\text {th }}$-day embryo. Less number of up-regulated (1557) and down-regulated (1157) transcripts were commonly differentially expressed on the $18^{\text {th }}$-day of the thigh muscle. Five commonly differentially expressed (545 up-regulated and 381 down-regulated) transcripts were identified among the embryo development stages, respectively (Fig. 1d, e; Supporting Document1\&2).

\section{Cluster analysis of differentially expressed transcripts}

To profile the gene expression patterns in response to muscle slow growth during embryo development, the 19022 DETs were classified using hierarchical clustering. The expression patterns were separated into eight major clusters (I-VIII) based on tree branching (Fig. 2). Transcripts present in each stage within each cluster are presented in Supplementary Table S1. Among the eight major clusters, upregulated transcripts were enriched in cluster V, VI and VII and downregulated transcripts were enriched in cluster II, III and IV.

\section{Expression of muscle related genes}

The difference in fast and slow growth is generally dependent on the combination of environment and genes. The embryos collected in this experiment are under the same growth environment. In this experiment, the DEGs related to the main cause of growth and development differences mainly include muscle system process, muscle tissue morphogenesis and muscle organ morphogenesis, etc. (Fig. 4). The genes enriched by these entries are mainly muscle-related genes such as TNNC1, TNNT2, MYL3, MYH7, and FBX032. The contraction of skeletal muscle-related genes is TNNC1, TNNT2, MYL3, and MYH7. In animals, skeletal muscle contraction affects the growth traits like muscle protein, muscle fibre diameter, and muscle fibre density [52, 53]. In the corpus callosum, muscle is the most important component and the sarcomere is composed of thick and thin muscles. Myosin molecules are mainly involved in thick filament formation and the thin filament is a complex containing troponin, actin, and tropomyosin [54]. The skeletal muscle contraction is mainly based on the relative sliding of thick and thin filaments [55]. For controlling the poultry muscle, according to previous reports, the troponin family gene is an important candidate gene $[52,56,57]$. In this experiment, the DEGs obtained related to the troponin family and important components of skeletal muscle are troponin T type 3 (TNNT3), slow muscle troponin T (TNNT1), and troponin I type 1 (TNNI1). The myosin superfamily is a highly conserved family of proteins and is composed 
of a heavy chain, an alkaline light chain, and a light chain and that is widely present in eukaryotic cells [58]. In striated muscle, smooth muscle, and nonmuscle, the myosin is involved in myofilaments as a class II. The MYH gene family is a key subunit in the myosin class II molecule and encoded the myosin heavy chain (MYHC) [59]. The studies revealed that MYH7 gene mutations could cause skeletal muscle disease or skeletal muscle disease with cardiomyopathy $[60,61]$. In the chicken breast muscle, the MYH7 gene expression is high and it is a hypothesis that it has a regulatory role in muscle tissue growth and development [62]. MYL3 gene is primarily expressed in slow muscle and it is a member of the myosin light chain (MYL) gene family [63]. Inhibition of myosin light chain gene expression in cell lines showed myoblast proliferation [64]. The chicken embryonic leg muscles proteome analysis found that MYL3 protein is closely related to the regulation of muscle contraction and the long non-coding RNAs Inc00037615 and Inc00037619 together regulate the muscle development [65]. In this experiment, the DEGs obtained related to the myosin family are MYH7 and MYL3. In this study, five genes related to muscle contraction were screened i.e. TNNT3, TNNT1, TNNI1, MYL3, and MYH7. Transcriptome study showed that the expression of these five genes is high in improved Aseel slow growth compared with control broiler fast growth. Also, these genes simultaneously present in two significantly enriched pathways i.e. adrenergic signaling in cardiomyocyte and cardiac muscle contraction. Maybe due to the upregulation of these genes and down-regulation of the Adrenergic signaling in cardiomyocyte and cardiac muscle contraction, improved Aseel will grow slow compare to the control broiler. Previous studies showed that in animals under fasting, FBXO32 gene expression was significantly increased and muscles were degraded due to lack of food, and maybe it is associated with muscle atrophy $[66,67]$. The FBXO32 gene expression was found in chicken's leg muscle, heart, and chest muscle and plays an important role in the $7^{\text {th }}$-week growth of chickens [68]. In this experiment, the results of transcriptome data showed that the expression of FBX032 and FBX07 genes were significantly lower in slow-growth improved Aseel than that in the fast-growth control broiler, which was consistent with previous studies. The DEGs KEGG pathway enrichment analysis revealed three significantly enriched adrenergic signaling in cardiomyocytes, Cardiac muscle contraction, and tight junction signaling pathways. In cell junctions, the tight junction is an important component and it acts as a barrier for cells to pass ions and molecules, plasma membrane apical movement regulation, and basal proteins and lipids $[69,70]$. In all eukaryotic cells, tight junction recognized as the actin cytoskeleton and it is involved in cell division, adhesion, movement, and phagocytosis and also found in chicken leg muscle transcriptome [71, 72]. The muscle growth epigenetic transcriptional regulators are differentially regulated in $7^{\text {th }}$ such as protein arginine N-methyl transferase family (PRMT1, and PRMT3), histone lysine N-methyl transferases (EHMT1, and SETDB1), SWI/SNF chromatin-remodeling enzymes (SmarcB1, and SmarcaA4).

\section{Muscle Development and Myostatin Signaling}

The muscle development and differentiation-related genes like MYOD1, MYF6, MYF5, Myoz2, MAP2K6, MAP3K7, CAV1, CAV2, CAV3, HSP70, and NCF2 were differentially regulated in slow-growing improved Aseel then compared to fast-growing control broiler (Fig. 4). In muscle differentiation, MYOD1 promotes the muscle-specific gene expression and function together with MYF5 and MYOG [73]. MYOD1 combined with transient placeholder protein, prevents the binding of other transcription factors to DNA, and retains the inactive conformation of the DNA [74]. One of the key functions of MYOD is to stop the differentiated myocytes proliferation by enhancing the transcription of p21 and myogenin to remove cells from the cell cycle [75]. Altogether, up-regulation of MYOD1 involved in skeletal muscle phenotype establishment by regulation of precursor cell proliferation and promoting irreversible cell cycle arrest, facilitate differentiation and sarcomere assembly by activation of sarcomeric, and muscle-specific genes [76]. In this study, transcriptome data shows down-regulation of MYOD1 in the $7^{\text {th }}$ day improved Aseel embryo, maybe due to this reason the muscle-specific gene proliferation is slow in improved Aseel. The myozenin is a a-actinin- and $y$-filamin-binding protein of $Z$ line skeletal muscle binds to calcineurin, and involved in skeletal muscle myocyte differentiation [77, 78]. Therefore, the up-regulation of MYOZ2 and MYOZ3 genes in muscle tissues suggested that they are involved in muscle growth and development and directly influence meat quality. Besides, MYOZ1 and MYOZ2 genes expressed in mice showed a significant reduction of calcineurin gene expression [79,80,81]. Our transcriptome study shows less expression of the MYOZ2 gene and high expression of regulator of calcineurin $1 \mathrm{gene}$ in $7^{\text {th }}$ day improved Aseel embryo, maybe this is the region the muscle development is slow in improved Aseel. Mitogen-activated protein kinases are major components of pathways controlling embryogenesis, cell differentiation, cell proliferation, cell death, muscle development, and response to environmental stress (Fig. 8) [82,83,84,85]. The MAP2K6 and MAP3K7 activate MAP kinase and nuclear factor-kappa $\beta$ (NFKB) and play an important role in its signal transduction pathway, respectively [86, 87]. In a proteomic study, predicted the expression of MAP2K1, MAP2K2, and MAP2K4, MAP4K4 gene may inhibit the low feed efficiency phenotype [88]. In our transcriptome data, the mitogen-activated protein kinase family genes are up-regulated in the $7^{\text {th }}$-day embryo of improved Aseel. Our results correlating with these results and maybe in this region the improved Aseel has less feed efficiency and slow muscle growth.

In this study, the expression of caveolin family genes like CAV1, CAV2, and CAV3 was downregulated in the $7^{\text {th }}$-day embryo of improved Aseel. In cell signaling, the caveolin genes act as sub-cellular structures by assisting the attribute of hormonal signals after binding hormone to the target receptor on the cell surface. The CAV3 is acting as a muscle-specific isoform for the caveolin protein and mutations or different expressions of CAV3 can result in muscle myopathies [89, 90]. In pigs, the CAV3 expression was up-regulated during muscle hyperplasia and it may use as a genetic marker for meat production in swine [91]. In mouse, the high or low expression of CAV3 made muscle cells more susceptible to oxidative stress and reduced survival through $\mathrm{PI}(3) \mathrm{K} / \mathrm{Akt}$ signaling [92]. In the low FE PedM broiler phenotype, the higher expression of CAV3 contributed to higher oxidative stress and enhance muscle development [93]. In high FE breast muscle, the CAV1 protein is involved in insulin signaling [88]. Based on previous reports, down-regulation of caveolin family genes in the $7^{\text {th }}$-day embryo of improved Aseel, maybe the improved Aseel muscle development will be reduced. In high FE breast muscle, the up-regulation of HSP70 maintains muscle fibre integrity and enhances muscle regeneration and recovery from damage [94]. HSP70 is also responsible for correct folding and assembly of nuclear-encoded proteins an important chaperone for mitochondrial DNA-encoded proteins as components of the mitochondrial electron transport chain targeted for import into the mitochondria $[95,96]$. In low and high FE phenotype, higher expression of HSP90 and HSPB2 was in response to oxidative stress, respectively [3, 88]. In our transcriptome study correlated with previous studies and we observed up-regulation of HSP70 and HSPB1 on the $7^{\text {th }}$-day and down-regulation of HSP90 on the $18^{\text {th }}$-day of improved Aseel embryo. Maybe the improved Aseel muscle is growing this region slowly compared to the control broiler. In NADPH oxidase 2 (NOX2), the NADPH/NADH oxidase is a critical component and encoded by neutrophil cytosolic factor 2 (NCF2) [97]. In muscle, superoxide was generated by NOX2 in the sarcoplasmic reticulum, and it is a major source of oxidative stress [97, 98]. In neutrophils, NADPH generated superoxide during phagocytosis. The nuclear factor erythroid 2-like 2 (NFE2L2) is a downstream target for NOX2 and activates genes that contain an antioxidant response element in their 
promoter regions $[99,100]$. In high FE animals, predicted the NFE2L2 expression should be upregulated [5, 88]. In a high FE commercial broiler, the upregulation of NCF2 was associated with muscle remodeling and hypertrophy [5]. In our transcriptome data, the NCF1, NOX1, and NOX3 were up-regulated on the $7^{\text {th }}$-day and NCF2 was down-regulated on the $18^{\text {th }}$-day of improved Aseel embryo. Maybe due to the differential expression of these genes, the improved Aseel is more resistant to oxidative stress, low FE, and slow growth.

Myostatin is a member of tumor growth factor $\beta$ (TGF- $\beta$ ) and is known as growth/differentiation factor 8 (GDF-8) [101, 102]. In the myostatin (MSTN) signaling pathway, MSTN binds to its receptors ActlIA/ActlIB and activates ALK4 and ALK5 that phosphorylate Smad2/3 leads to its binding with Smad4 and translocation of the complex to the nucleus and where it blocks the transcription of genes responsible for the myogenesis $[103,104,105,106,107](F i g .8)$. The myostatin is solely expressed in skeletal muscle during embryogenesis to control the differentiation and proliferation of the myoblasts [101]. However, in the adult stage, it is not only expressed in skeletal muscle but also expressed in other tissues like the heart, adipose tissue, mammary gland

$[101,108,109,110,111,112]$. In turkey satellite cells, MSTN is a strong negative regulator for skeletal muscle growth, differentiation, and proliferation [101, 113]. The relation between MSTN and growth performance studies in broilers shows that MSTN is a polymeric gene in which different alleles of the gene can affect performance [114,115,116]. In PedM broiler, the FE differences may be due to different haplotypes of the MSTN gene [107]. Myostatin knockdown by RNAi shows muscle growth enhancement in transgenic sheep and chicken $[117,118,20]$. In the present study, MSTN has differentially regulated in the $7^{\text {th }}$-day improved Aseel embryo. Maybe differential regulation of myostatin is need for myoblasts differentiation and proliferation in initial embryogenesis. Follistatin (FSTN) regulates the MSTN by inhibiting or limit the MSTN activity. Follistatin-like 1 (FSTL1) is a glycoprotein and rich in cysteine (SPARC) family and comprises a secretion signal, a Follistatin- and a Kazal-like domain, two EF-hand domains, and a von Willebrand factor type C domain [119] (http://www.uniprot.org/uniprot/Q12841). In mouse, the FSTL1 were broadly expressed throughout the entire embryo and restricted most of the tissues at the end of gestation but in the adult mouse, it is highly expressed in heart, lung, and subcutaneous white adipose tissue [120, 121]. In this present study, FSTL1 was up-regulated and follistatin/kazal down-regulated in the $7^{\text {th }}$ and $18^{\text {th }}$-day of improved Aseel embryo, respectively. Initial up-regulation and later downregulation of FSTL1 may initiate muscle proliferation in the $7^{\text {th }}$-day embryo and $18^{\text {th }}$-day embryo slowdown the muscle development in improved Aseel. In humans, activin receptor type-1B (ACVR1B) or ALK4 is a protein that acts as a transducer of activin or activin-like ligand signals [122]. ACVR1B forms a complex with ACVR2A/ACVR2B and goes on to recruit the SMAD2/SMAD3 [123]. Besides, ACVR1B transduces nodal, GDF-1, and Vg1 signals combined with other coreceptor molecules like protein cripto [124]. Transforming Growth Factor- $\beta$ (TGF $\beta$ ) is a key player in cell proliferation, differentiation, and apoptosis and TGF $\beta$ receptors are single-pass serine/threonine kinase receptors and can be eminent by their structural and functional properties [125]. Due to the similar ligand-binding affinities, the transforming growth factor beta receptor I (TGF $\beta$ R1)/ALK5 and TGF 32 can be distinguished from each other by peptide mapping only. In mouse, the TGF $\beta 1 \mathrm{mRNA}$ /protein has been present in cartilage, endochondral, membrane bone, and skin and play a role in the growth and differentiation of these tissues [126] (Fig. 8). In the present study, activin A receptor type IB (ALK4) and transforming growth factor beta receptor II (TGFBR2) were up-regulated, and transforming growth factor beta receptor I (TGFBR1/ALK5) was down-regulated in the $7^{\text {th }}$-day embryo of improved Aseel. The differential expression of ALK4 and ALK5 may control the myostatin signaling pathway. The SMADs are important for regulating cell development and growth and they have structurally similar proteins and main signal transducers for TGF $\beta$ receptors (Fig. 8). The eight SMAD genes are distributed into three sub-types of SMADs, they are R-SMADs, Co-SMADs, and I-SMADs [127, 128]. The R-SMADs consist of Smad1, Smad2, Smad3, Smad5, and Smad8/9 and are involved in direct signaling from the TGF $\beta$ receptor $[129,130]$. The Co-SMADs consist of the only SMAD4 and working jointly with R-SMADs to recruit co-regulators to the complex [131]. R/Co-SMADs are primarily located in the cytoplasm, following TGF $\beta$ signaling later accumulate in the nucleus, where they can bind to DNA and regulate transcription. I-SMADs consist of SMAD6 and SMAD7 and are predominantly found in the nucleus, and they can act as direct transcriptional regulators. SMAD6 has specifically associated BMP signaling and SMAD7 is a TGF $\beta$ signal inhibitor and suppresses the activity of R-SMADs [132,133,134]. In the present transcriptome study, the SMAD family member 1 (SMAD1), SMAD specific E3 ubiquitin protein ligase 2, SMAD family member 3 (SMAD3), SMAD family member 5 (SMAD5), TGF-beta signal pathway antagonist Smad7 (SMAD7B) up-regulated in $7^{\text {th }}$ day of improved Aseel embryo and they may control the myostatin signaling pathway in improved Aseel embryonic stage. Summarizes the initial steps in the MSTN signaling pathway in the present study that would potentially exert a negative effect on muscle differentiation and proliferation in the slow-growing improved Aseel.

\section{Energy Sensing}

In humans and animals, the adenosine monophosphate-activated protein kinase (AMPK) gene regulates diverse biological functions [135]. The mammalian 5 AMPK gene has two a subunits i.e. AMPKa1 and AMPKa2 that are encoded by Prkaa1 and Prkaa2 gene, respectively. The knockout mouse clearly demonstrated that the AMPKa2 controls the homeostasis in skeletal muscle [136, 137]. Also observed reduction of fibre numbers ( 25\%) and sizes ( 20\%) in the soleus muscle of AMPKa1 knockout mice [138]. However, in AMPKa2 knockout mice, both fibre size and muscle mass were significantly increased, while the muscle fibre number has remained similar to WT animals. The muscle mass reduced and increased differentially expressed alternative polyadenylation sites (DE-APSs) were down-regulated in AMPKa1 knockout mice, but up-regulated in AMPKa2 knockout mice, respectively [46]. The five genes i.e. carbonic anhydrase 3 (Car3), myosin light chain kinase family, member 4 (Mylk4), nebulin (Neb), obscurin (Obscn), and phosphofructokinase, muscle (Pfm) are utilized different APSs showed potential effects on muscle function [46]. The high FE phenotype birds show up-regulation of both AMPKa1 and AMPKa2 [3]. In low energy level conditions the AMPK genes expression increases for ATP production by inhibiting the ATP consuming pathways like fatty acid synthesis, protein synthesis, and gluconeogenesis and stimulates the ATP producing pathways like mitochondrial biogenesis and oxidative phosphorylation, glycolysis, and lipolysis $[139,140,141]$. In the present study, the AMPK genes like 5'-AMP-activated protein kinase gamma-1 non-catalytic subunit variant 1 (PRKAG1), protein kinase cAMP-dependent regulatory type I alpha (tissue specific extinguisher 1) (PRKAR1A), protein kinase AMP-activated beta 2 non-catalytic subunit (PRKAB2), protein kinase AMP-activated gamma 2 non-catalytic subunit (PRKAG2), carbonic anhydrase XIII, myosin light chain kinase (MYLK), atrial/embryonic alkali myosin light chain, are down-regulated in the $7^{\text {th }}$-day of improved Aseel embryo, maybe due to the down-regulation of energyproducing pathways, the improved Aseel muscle will grow slowly compare to control broiler. Curiously, creatine kinase (muscle isoform, CK-M) and creatine kinase (brain isoform, CK-B) were up-regulated in high and low FE phenotype, respectively $[88,142,143]$. The reason for this discrepancy may be the high FE 
phenotype broiler breast muscle has enhanced capabilities for mitochondrial oxidative phosphorylation as well as creatine and phosphorylated creatine shuttle in and out of mitochondria [143]. In the present study, the creatine kinase muscle (CKM), creatine kinase mitochondrial 1A (CKMT1A), creatine kinase brain (CKB), creatine kinase, mitochondrial 2 (sarcomeric) (CKMT2) genes were up-regulated in the $7^{\text {th }}$-day embryo of improved Aseel. In skeletal muscle, nitric oxide was synthesized by nitric oxide synthases and it is regulated key homeostatic mechanisms like mitochondrial bioenergetics, network remodeling, mitochondrial unfolded protein response (UPRmt), and autophagy (Fig. 4; Fig. 5). In mice, nitric oxide synthase deficiency inhibits the Akt-mammalian target of the rapamycin pathway and dysregulated the Akt-Fox03-mitochondrial E3 ubiquitin-protein ligase 1 (Mul-1) axis [144]. Thus, the mitochondrial biogenesis and body energy balance were controlled by the nitric oxide-cGMP-dependent pathway [145]. In detail, the inhibition of nNOS/NO/cGMP-dependent-protein kinases enhanced the FoxO3 transcriptional activity and increased the Mul-1 expression. The absence of the nitric oxide synthases significantly impaired muscle fibre growth with muscle force, decreased resistance to fatigue, and degeneration/damage post-exercise. In our study, nitric oxide synthase 2 was up-regulated and, cGMP-dependent protein kinase type I, and FOX01 was down-regulated in the 7th-day of improved Aseel embryo, maybe this is the region, the improved Aseel muscle strength was high and they are more energetic compared to the control broiler.

The comparative muscle transcriptome analysis between high and less $\mathrm{pH}$ chicken showed that most of the glycolysis pathway genes are up-regulated in the less $\mathrm{pH}$ chicken [146]. The previous study shows Aseel and broiler chicken's meat do not have any significant $\mathrm{pH}$ variation but the heavier bird's meat had a significantly higher $\mathrm{pH}$ [147]. In this study, glycolysis metabolism-related genes are differentially regulated on the $7^{\text {th }}$-day of improved Aseel embryo. The glucose-6-phosphate isomerase, fructose bisphosphate aldolase, phosphoglycerate kinase, and enolase were down-regulated and GAPDH, phosphoglycerate mutase, and pyruvate kinase were up-regulated in the $7^{\text {th }}$-day embryo of improved Aseel. Fructose bisphosphate aldolase is a key enzyme in glycolysis as well as gluconeogenesis and involved in the stress-response pathway during hypoxia [148]. The high pH chickens have increased oxidative stress, maybe the higher expression of fructose bisphosphate aldolase is linked to its function in the stress-response pathway rather than to its role in ATP biosynthesis [149]. In our study, down-regulation of fructose bisphosphate aldolase enhanced the ATP synthesis, maybe this is the region improved Aseel birds have more energy than control broiler. Noteworthy, the up-regulation of glycolysis pathway genes are increased the pyruvate levels and entering the citric acid cycle, and thus, higher levels of ATP are produced in improved Aseel. The protein phosphatase-1 regulatory subunit 3A (PPP1R3A) binds glycogen with high affinity, and activates glycogen synthase (GYS), and inhibits glycogen phosphorylase kinase (PHK) by dephosphorylation through the protein phosphatase-1 catalytic (PPP1C) subunit. In this study, the glycogen metabolism genes i.e. protein phosphatase-1 regulatory subunit 2 (PPP1R2), glycogenin 1, glycogen phosphorylase, and protein phosphatase-1 catalytic subunit beta (PPP1CB) were down-regulated in the $7^{\text {th }}$-day embryo of improved Aseel, maybe this is the region that the improved Aseel muscle have more glycogen. The AMP-activated protein kinase (AMPK) complex is another key regulator of glycogen turnover and it consists of one $\alpha$ catalytic and two non-catalytic subunits, $\beta$, and $\gamma$. The $\beta$ subunit binds to glycogen along with $\alpha$ and $\gamma$ subunits and forms a heterotrimeric AMPK complex. In the muscle cell, the y subunits of the AMPK complex act as energy sensors and binding to AMP and ATP [150]. In our study, AMP-activated protein kinase beta 2 non-catalytic subunit (PRKAB2), cAMP-dependent protein kinase regulatory type I alpha (tissue-specific extinguisher 1) (PRKAR1A), AMP-activated protein kinase gamma 2 non-catalytic subunit (PRKAG2) were down-regulated, and 5'-AMP-activated protein kinase gamma-1 noncatalytic subunit variant 1 (PRKAG1), AMP-activated protein kinase gamma 3 non-catalytic subunit (PRKAG3), AMP-activated protein kinase alpha 2 catalytic subunit (PRKAA2) were up-regulated. The down-regulation of $\beta$ subunits and up-regulation of $a$ and $y$ subunits may balance the glycogen accumulation and increase the ATP molecules for energy production in improved Aseel muscle, maybe this is the region the improved Aseel has more strong than the control broiler. Apart from these, several other genes indirectly influence glycogen storage in muscle. The phosphodiesterase 3B (PDE3B) gene activated by insulin and induce antiglycogenolytic effects and the mitochondrial creatine kinase (CKMT2) transfers the high-energy phosphate from mitochondria to creatine. In our study, phosphodiesterase 3A (PDE3A), phosphodiesterase 4D, phosphodiesterase 8A, mitochondrial creatine kinase 2 (CKMT2), mitochondrial creatine kinase $1 \mathrm{~A}\left(\mathrm{CKMT1}\right.$ ), mitochondrial creatine muscle (CKM) were up-regulated in the $7^{\text {th }}$-day of embryo improved Aseel, maybe this is the region, the higher expression of these genes in muscle, improved Aseel birds are more energetic compared to control broiler. To produce energy and compensate for the lack of energy due to carbohydrates and glycolysis, the high pH chickens muscle asks for more intense oxidative pathways, such as lipid $\beta$-oxidation and ketogenic amino acid degradation [149]. In the high pH muscle line, the 3-hydroxymethyl-3-methylglutaryl-CoA lyase (HMGCL) catalysis the final step of leucine metabolism and ketone metabolism, acetyl-CoA acetyltransferase-2 (ACAT2) involved in $\beta$-oxidation or degradation of ketogenic amino acids, and nudix hydrolases (NUDT7, NUDT12, NUDT19) hydrolyse a nucleoside di and triphosphates, dinucleoside and diphosphoinositol polyphosphates, nucleotide sugars and RNA caps, were up-regulated. In the present study, 3-hydroxymethyl-3-methylglutaryl-CoA lyase like-1 (HMGCLL1), acetyl-CoA acetyltransferase 2 (ACAT2), nudix type motif 7 (NUDT7), and nudix type motif 21 (NUDT21) were down-regulated and carnitine/palmitoyl-transferase 1 (CPT1) were up-regulated in the $7^{\text {th }}$-day embryo of improved Aseel (Fig. 6). They may regulate the $\beta$-oxidation in peroxisomes as well as mitochondria, this is the region may be fats required for initial embryo development and excess fats involved in $\beta$-oxidation and finally provide the energy for embryo development.

\section{Protein Synthesis}

To promote cell growth, the MTORC1 complex increases protein synthesis and lipid metabolism, and autophagy inhibition, and regulates the transcription of several genes [151]. In high FE phenotype, the cDNA microarray data shows higher expression of mTORC1 [152, 153]. The mTORC1 complex has two major components i.e. mTOR and RAPTOR [154]. The RAPTOR and mTOR were up and down-regulated in high and low FE birds, respectively, and the up-regulation of RAPTOR could be a positive effect on protein synthesis [154]. In low FE phenotype, the PRKAR1A and GLUT-8 were up-regulated. The p70S6k and eukaryotic translation initiation factor 4E (EIF4E) are the key downstream targets for mTORC1 and involved in enhancing the protein synthesis. In low FE birds, the expression o p70S6k was higher [155]. The muscle tissue of RNAseq transcriptomic data showed higher expression of eukaryotic initiation, elongation, and translation genes in high FE compared to low FE PedM phenotype [142, 156]. In the present study, the late endosomal/lysosomal adaptor MAPK and MTOR activator 3 (LAMTOR3), protein kinase, cAMP-dependent, regulatory, type I, alpha (tissue specific extinguisher 1) (PRKAR1A), solute carrier family 2 (facilitated glucose transporter) member 8 (SLC2A8)/ GLUT8/ GLUTX1, solute carrier family 2 (facilitated glucose transporter), member 3 (SLC2A3), ribosomal protein S6 kinase, 90kDa, polypeptide 1 (RPS6KA1), ribosomal protein S6 kinase, 90kDa, polypeptide 3, ribosomal protein S6 kinase, $52 \mathrm{kDa}$, polypeptide 1 , ribosomal protein $\mathrm{S} 6$ kinase, $90 \mathrm{kDa}$, polypeptide 6, ribosomal protein S6 kinase-like 1, KIAA1328, KIAA1324, and eukaryotic translation initiation factor 4E 
binding protein 1 gene were down-regulated in the $7^{\text {th }}$-day embryo of improved Aseel compared to control broiler (Fig. 4). May be due to the down-regulation of mTORC1 complex and ribosomal machinery genes, the protein synthesis for muscle growth is less in improved Aseel compared to control broiler.

\section{Insulin Signaling}

In chicken, the SHC1 is only activated by nutritional changes and suggesting that insulin signaling in chickens have a tissue-specific manner [157, 158]. When insulin binds to the insulin receptor, both IRS-1 and SHC1 are activated by a phosphoinositide-3 kinase (PI3K) mediated tyrosine phosphorylation activity [3]. The skeletal myoblast is mainly differentiated by two key modulators i.e. insulin-like growth factor 1 (IGF1) and fibroblast growth factor 2 (FGF2) [159, 160]. In L6 and C2C12 myoblasts, a high concentration of IGFs reduces their differentiation, whereas a low concentration enhances their differentiation [161, 162]. The IGF binding proteins (IGFBP-1 to IGFBP-6) have highly conserved regions and binds with high affinity to IGF-1 and IGF-2. In the extracellular matrix, IGFBP3 may regulate the interaction of IGFs and it is present in rat soleus muscle (type I muscle fibre) [163, 164]. In humans, IGFBP3 was also playing a role in myoblasts differentiation [165]. The fibroblast growth factor 2 (FGF2), transforming growth factor beta (TGFb), and oncogenic Ras also inhibit the skeletal myoblast differentiation [160]. In 23A2 myoblast cell lines, showing the inhibition of 23A2 myoblasts differentiation by IGF1 and FGF2 by stimulating the signaling through mitogen-activated protein kinase (MAPK) kinase (MEK) to MAPK [166]. In our study IGF2, FGF2, IGFBP2, IGF2BP1, IRS-1, IRS-2, INSIG1, PIK3CA, PIK3CD, TGFb, and Ras oncogene family genes are up-regulated in the $7^{\text {th }}$-day embryo of improved Aseel (Fig. 7). Maybe this is also one of the regions for improved Aseel muscle is differentiated slowly when compared to the control broiler.

\section{Expression of plumage development genes}

In vertebrate coloration, melanin pigmentation is an important component and regulated by strong genetic control [167, 168]. In chicken, the plumage coloration development is extremely complex and can be categorised as structural or pigment-based [169]. For animal colouration, melanin is a common component, synthesized in melanocytes, and deposited in various organs as granules [170]. Different pigment patterns are formed based on the presence of melanocytes modulating, arrangement or differentiation, and associated with a series of functional genes [171, 172]. The melanogenesis genes such as HOX, CHAC1, GPX3, BMP5, PITX2, RGN, MITF, TYR, KIT, OCA2, ASIP, MCIR, KITLG, IRF4, SLC24A4, SLC45A2, EDN, TYRP1, and TYRP2 are involved in melanin pigmentation $[173,174,175,176,177]$. The homeobox $(\mathrm{HOX})$ genes are transcription factors and involved in skin appendages development including hair follicles and feathers $[178,179,180,181,182,183]$ (Fig. 8). In black-bone chickens, four HOX genes i.e. HOXB9, HOXC8, HOXA9, and HOXC9 were identified for melanin pigmentation [172]. The Wnt signaling is essential for skin organogenesis and its appendages like hairs, feathers, and scales, melanocyte development, and differentiation [184,185,186,187]. The HOXB9 is identified as a target gene for Wnt signaling and HOXC8 is expressed in the first stage of feather morphogenesis like dorsal dermal and epidermal cells $[188,189]$. In this study, HOXA2, HOXA9, HOXB3, HOXB5, HOXB7, HOXB8, HOXB9, HOXC11, HOXD1, and HOXD3 are up-regulated in the $7^{\text {th }}$-day improved Aseel embryo, maybe this is the region the improved Aseel plumage has multiple colors.

In animals, melanogenesis is regulated by GSH and it is closely associated with melanin deposition in the skin of humans and other mammals $[190,191,192,193,194]$. The low and high level of GSH indicates eumelanin-type pigmentation and phaeomelanin-producing melanocytes found in skin, respectively [195]. Two feather melanin pigmentation genes were identified in black-bone chickens such as ChaC glutathione-specific gammaglutamylcyclotransferase 1 (CHAC1) and glutathione peroxidase 3 (GPX3) [172]. The CHAC1 cleavage GSH into 5-oxoproline and Cys-Gly dipeptide and GSH over-expressed mammalian cells caused GSH depletion [196, 197]. Hence, CHAC1 expression is associated with GSH metabolism and plays an important role in the melanogenesis process. In eumelanin and phaeomelanin synthesis, the hydrogen peroxide reduced by GSH-dependent peroxidase and GPX3 belongs to the GSH peroxidase family and catalyzes the GSH to glutathione disulphide (GSSG) $[194,198]$. The melanoma cells pigmentation regulated by GSH levels, glutathione peroxidase, and glutathione reductase suggesting that GSH mediated redox process plays an important role in melanogenesis regulation [199]. Hence, the expression of GPX3 plays an active role in chicken feather melanogenesis. In this study, CHAC1, CHAC2, gamma-glutamylcyclotransferase (GGCT), and GPX8 were down-regulated on the $7^{\text {th }}$-day of improved Aseel embryo, maybe this is the region the improved Aseel has multiple colors on their feathers. In black-bone chicken, two pathways i.e. TGF- $\beta$ signaling pathway, and ascorbate and aldarate metabolism were identified for plumage melanogenesis [172]. The TGF- $\beta$ involved in the regulation of chicken retinal pigment epithelial cell proliferation and melanin synthesis [200]. The BMP5 and PITX2 genes are involved in the TGF- $\beta$ signaling pathway and play a role in chicken melanin synthesis, and the BMP5 and PITX2 were highly expressed in white feather and black feather bulbs, respectively [200]. The BMP3 gene was highly expressed in embryonic and post-embryonic stages of control layer when compare to broiler chicken and BMP4 gene was differentially expressed in juvenile stages of broiler and layer chicken, respectively [201, 202]. The regucalcin (RGN) is a calciumbinding protein involved in the ascorbate and aldarate metabolism pathway and plays a crucial role in intracellular calcium homeostasis maintains [203]. In this study, transforming growth factor beta receptor II (TGFBR2), BMP1, BMP1A, BMP4, BMP7, BMPR1A, BMPR2, PITX3 up-regulated and RGN was downregulated in the $7^{\text {th }}$-day embryo of improved Aseel, maybe this is the region the improved Aseel plumage has multiple colors.

In melanin synthesis, TYR is a rate-limiting enzyme and involved in different oxidative steps [204, 205]. In black vs. white skin chicken, the TYR is highly expressed and it is consistent with sheep coat color studies [173,206,207]. In black-coated vs. white-coated sheep, the TYRP1 gene was highly expressed [207]. KIT is a receptor tyrosine kinase, the mutation in KIT showed piebaldism and auburn hair color in humans and it plays an important role in UVB-induced melanogenesis in the epidermis, and inhibition of KIT expression may result in the lighten human skin color [208, 209]. In black skin chicken, KIT is highly expressed and black skin color is due to increased melanin compared to the white skin color [173]. In melanocytes development, microphthalmia-associated transcription factor (MITF) is playing a role and mutations in the MITF gene is responsible for Japanese quail and chicken plumage color and it is supported to alternative splicing of MITF gene in the skin of sheep [210, 211]. In ducks, the TYR and MITF expression may involve in the formation of black and white plumage [212]. Melanocortin-1 receptor (MC1R) is binding to melanocyte stimulating hormone (MSH) and initiates the melanogenesis cascade and regulates the mammalian skin pigmentation and hair color $[213,214,215,216]$. The agouti signaling protein (ASIP) is responsible for the skin color of both white and black-coated sheep and mutations in ASIP cause black and tan pigmentation phenotype in pigs [206, 217]. The ASIP binds to MC1R and reduced the MITF and TYR gene expression and finally, the phaeomelanin would be reduced in epidermal tissues. In black-skinned chickens, the expression of ASIP is higher than compared to the white-skinned chicken and it can suppress the MC1R gene expression in black-skinned chickens [173]. The Oculocutaneous albinism 
type 2 (OCA2) is a common skin pigmentation disorder caused by a mutation in the OCA gene. In black chickens, the OCA2 was up-regulated and it may be related to black skin color [173]. In chickens, the endothelins (EDN1, EDN2, and EDN3) and their receptors (EDNRA, EDNRB, and EDNRB2) are involved in the regulation of pigmentation and plumage [218]. The expression of EDNRB2 was significantly different between adult black and non-black chicken [219]. In this study, TYRP1, KITLG, MITF, MC1R, AGRP, YRK, and P56LCK were up-regulated and EDNRA and EDN1 were down-regulated in the $7^{\text {th }}$-day of improved Aseel embryo and this is the region the improved Aseel plumage has multiple colors.

\section{Expression of genes related to egg production}

In chicken, the reproductive system is regulated by hypothalamic-pituitary-ovarian (HPO) axis hormones, while ovulation, the GnRH-I triggers the pituitary gland to release $\mathrm{FSH}$ and $\mathrm{LH}$, and stimulates the secretion of estradiol and progesterone in the ovary [220]. Several reproductive hormone regulation genes were identified between high and low egg production chickens, such as HADH, HMGCR, RAB11FIP1, and FAM3D [221]. In the pituitary gland, lipid metabolic process, prolactin and, MAPK signaling pathway genes i.e. HMGCR, HMGCS1, NFKB1, VAV3, SOS1, IL1R1, MEF2C, STK3 were highly expressed. In chicken, the anterior pituitary gland synthesized and released prolactin and involved in reproduction, laying eggs, metabolism, development, and hypothalamic-pituitary-gonadal axis regulation $[222,223]$. In chicken, the HMGCR gene variants (G-789-A, C-937-G, and A-2316-C) and high and low concentrations of VLDL showed higher and lower egg production, respectively [224]. In laying chickens, the APOB is a primary organizing protein for chylomicrons and VLDL and responsible for the transport of lipoprotein and circulating in the plasma, and stored into the oocytes to form an egg yolk [225, 226]. In our study, GNRHR, HADHB, HMGCS1, HMGCS2, RAB11FIP2, RAB11FIP3, RAB11FIP4, NFKB2, VAV2, SOS2, MEF2D, STK3, PRL, PRLR, PRLH, and PRLHR2 genes were up-regulated, and FSHR, VAV3, IL1RL1, and IL1RAPL2 genes are down-regulated, and family with sequence similarity genes and apolipoprotein B were differentially regulated in the $7^{\text {th }}$-day embryo of improved Aseel. Maybe this is the region the improved Aseel has less egg production than the commercial chicken. In avian species, the genes SPP1, BPIFB3, and EDIL3 are mainly involved in egg and oviposition, development of reproduction system, and vesicle-mediated eggshell calcication, respectively $[227,228,229,230]$. In this study, secreted phosphoprotein 1 (SPP1) and secreted phosphoprotein 2 (SPP2) genes are down-regulated, and EDIL3 is up-regulated in the $7^{\text {th }}$-day of improved Aseel embryo, due to this, egg and oviposition are less and eggshell calcication is more in improved Aseel. In nandanyao chicken, FN1, FGF7, SOX2, ALDOB, HSPA2 genes are expressed in the ovary, and UQCRH, COX5A, FN1, TGFB, ACTN1 genes are expressed in the uterus and involved in egg production [231]. In this study, FN1, FNDC3A, FGFR1, FGFR3, FRS3, FRS2, FGFR2, FGFRL1, FGF8, FGF18, FGF3, FGF12, SOX2, SOX3, SOX4, SOX5, SOX7, SOX8, SOX9, SOX11, SOX17, HSPA2, HSPA4, COX1, COX2, COX3, TGFB4, and ACTN1 were up-regulated and ALDOB, HSPA5, HSPA8, HSPA9, HSP12A, UQCRFS1, UQCRB, were down-regulated in the $7^{\text {th }}$-day improved Aseel embryo. The differential expression of the ovary and uterus related genes are differentially expressed in the $7^{\text {th }}$-day of improved Aseel embryo, due to this region the egg production is less in improved Aseel. The DEGs related to the pituitary gland between high and low egg production chickens are mainly involved in mTOR and Jak-STAT signaling pathways [221]. In mouse, the mTOR signaling pathway will regulate the granulosa cell proliferation and differentiation [232]. In this study, the mTOR and Jak-STAT signaling pathways were upregulated in the $7^{\text {th }}$-day improved Aseel embryo.

In high egg production chickens, several embryonic development genes are up-regulated such as GDNF, HOXD9, MEF2C, STK3, CLRN1, IRX5, LBX1, CSNK1A1, LGR5, PRDM15, and DAB2IP [221]. In this study, the GDNF, HOXA2, HOXB3, HOXB5, HOXB7, HOXB8, MEF2D, STK3, STK16, STK25, STK32B, IRX1, IRX2, IRX5, IRX6, LBX1, LBX3, PACSIN2, RGR, PRDM4, PRDM8, and DAB2IP genes are up-regulated in the $7^{\text {th }}$-day of the embryo, these genes are involved in embryo development. In the ovary, the tryptophan metabolism and PI3K-Akt signaling pathways were enriched and they are important for egg production [221] (Fig. 8). In stressful conditions, peripheral and brain tryptophan levels can alter by stimulating the immune system and activating the hypothalamic-pituitary-adrenal axis $[233,234]$. In this study, tryptophan metabolism was down-regulated in the $7^{\text {th }}$-day of the embryo and up-regulated in the $18^{\text {th }}$-day thigh muscle, this is the region the improved Aseel has less egg production. In high egg productions, the hypothalamus genes are highly expressed such as EXFABP, SNRNP25, FAM114A1, and SIX1 [221]. In the hypothalamus, nerve growth factor response, lipid metabolism, canonical Wnt signaling pathway genes were highly expressed i.e. SIX1, RPS15, IGFBP7 thus play a role in chicken egg production. In laying hens, the dietary corticosterone treatment shows low levels of extracellular fatty acid-binding protein (EXFABP) and suggested that the egg white proteins synthesis and secretion may effect by environmental stress [235]. Many studies reported that ovarian follicular development is stimulated by IGFBPs and plays a role in the ovary to FSH action [236, 237]. In chicken adipose tissue, the lipid metabolism gene like insulin-like growth factor binding protein 7 (IGFBP7) was highly expressed and it is correlated with egg production [238, 239]. In this study, FAM114A, FAM116A, FAM116B, FAM117A, FAM117B, SIX1, SIX2, RPS13, RPS24, IGFBP2, IGFBP3, and IGFBP5 genes are up-regulated and FABP1, FABP2, FABP3, FABP5, SNRPB, SNRPB2, IGFBP1, and IGFBP7 genes are down-regulated in the $7^{\text {th }}$-day embryo of improved Aseel, these differentially expressed genes may cause less egg production in improved Aseel (Fig. 7). The cuticle or organic matrix of the eggshell-related genes i.e. MEPE, BPIFB3, RARRES1, and WAP are highly expressed in oviposition [240,241,242]. In this study, RARA, RARB, POSTN, CDH4, CDH13, CDH8, CDH11, and CDH20 were upregulated, and RARRES1, and $\mathrm{CDH} 1$, were down-regulated in the $7^{\text {th }}$-day improved Aseel embryo. Due to the differential expression of these genes may be the improved Aseel eggshell thickness is more than commercial laying eggs.

The mitochondrial oxidative phosphorylation, active transport, and energy-metabolism related genes such as NADH dehydrogenase, ND4, ND1, ND2, ND5, ACTB, GAPDH, ATP6, and ATP1A are required for a large amount of energy, and active secretion of proteins and minerals [243]. A recent report shows differential expression of these genes like MEPE, COX1, COX3, COX2, BPIFB3, Cytochrome b, ATP6, ND5, ATP1A1, ND4, ND2, EIF4A2, UBB, Novel mitochondrial gene, IGLL1, HSPA8, RASD1 in GNRH1 vs. AVT study [244]. In this study, ND1, ND2, ND3, ND4, ND4L, ND5, ND6, GAPDH, ATP6, ATP1A2, COX1, COX2, COX3, and CYTB were up-regulated, and NDUFAF1, NDUFA4, NDUFA5, NDUFA9, NDUFA10, NDUFAF4, ATP1A1, EIF4A2, COX15, COX19, COX20, CYB5A, CYB5B, and CYB5R2 were down-regulated in the $7^{\text {th }}$-day of the improved Aseel embryo. Most of the energy metabolism genes are up-regulated and may be the region improved Aseel is stronger than commercial birds.

\section{Conclusion}


The comparative transcriptome study between slow growth improved Aseel and fast growth control broiler revealed the DEGs and their significantly enriched pathways in slow growth improved Aseel, which inferred that they play an important role in regulating the growth and development of improved Aseel. The transcriptome data provides a theoretical basis for improving the performance of the slow growth improved Aseel as well as how to control the growth performance in fast grown control broiler chicken and provides reference data for revealing the molecular mechanism of slow growth improved Aseel as well as fast growth control broiler chicken. In this study, the mechanistic picture of gene expression data shows the embryo development, muscle development, egg production, plumage development, and energy production in improved Aseel, which would be fostered by a combination of (a) Differential regulation of MSTN, activin-like kinases and up-regulation of SMADs expect SMAD7 in the myostatin signaling pathway combined with down-regulation of caveolin's (CAV1, CAV2, and CAV3) and differential regulation of insulin-like growth factor binding proteins, (b) Up-regulation of HSP70, NCF1, Map2k2, and down-regulation of MYOD1, and MYOZ2, (c) Up-regulation of fatty acid synthesis and $\beta$-oxidation genes (ACACA, ACACB, FASN, and CPT1), (d) Differential MAPK signaling pathway genes (MAP2K2, MKA, NES, SAMSN1, SOS2, and TAB2) (e) Differential regulation of Jak-STAT, mTOR, and TGF- $\beta$ signaling pathway genes (IGF1, IGF2, IRS1, IRS2, PI3K, Akt1, Akt2, Fox01, FoxO3, TSC22D1, TSC22D2, RHOA, RHOB, RHOC, RHOF, RHOQ and EIF4EBP1), (f) Differential regulation of mitochondrial genes (ND1, ND2, ND3, ND4, ND4L, ND5, ND6, ATP6, ATP1A2, COX1, COX2, COX3, CYTB NDUFAF1, NDUFA4, NDUFA5, NDUFA9, NDUFA10, NDUFAF4, ATP1A1, EIF4A2, COX15, COX19, COX20, CYB5A and CYB5B), (g) Differential regulation of glycolysis/gluconeogenesis genes (GCK, GPI, ALDOB, GAPDH, PGK1, PGAM5, ENO1, PKM2, and LDHB).

\section{Declarations}

\section{Author Contributions}

MK conducted wet lab experiment, data analysis and preparing first draft; RA performed wet lab experiment; RNC performed data analysis and prepared tables; TKB developed the idea, designed \& planned the research work, wet lab experiment and edited draft.

\section{Funding}

The corresponding author acknowledge the funding support rendered by the SERB, Department of Science \& Technology, Govt. of India to carry out the research work under the project (Project No. CRG/2018/002246).

\section{Acknowledgements}

The authors thankfully acknowledge the DST for funding the research work. We also render acknowledgment to Director, ICAR-DPR for providing logical support for this work. We acknowledge Genotypic Technology private Limited, Bangalore for the microarray processing and data analysis.

\section{Competing interest}

Authors do not have conflict of interests.

\section{Availability of data and materials}

All data generated or analysed during this study are included in this published article and its supplementary information files (Supporting Document 1 List of differentially pathways during embryo development stages (7th day embryo and 18th day thigh muscle) as compared to their respective control samples of control broiler and Supporting Document 2 Selected candidate reference genes and primers used for qPCR analysis).

\section{Ethics approval and consent to participate}

The whole experiment including all the protocols was approved by the Institute Animal Ethics committee (IAEC) of ICAR-Directorate of Poultry Research, Hyderabad, India.

\section{Consent for publication}

Not applicable

\section{References}

1. Niemann H, Kuhla B, Flachowsky G. Perspectives for feed-efficient animal production. J Anim Sci. 2011;89(12):4344-4363.

2. Kong BW, Song JJ, Lee JY, Hargis BM, Wing T, Lassiter K, Bottje W. Gene expression in breast muscle associated with feed efficiency in a single male broiler line using a chicken 44K oligo microarray. I. Top differentially expressed genes. Poult Sci. 2011;90(11):2535-47.

3. Bottje WG, Kong BW, Song JJ, Lee JY, Hargis BM, Lassiter K, Wing T, Hardiman J. Gene expression in breast muscle associated with feed efficiency in a single male broiler line using a chicken 44K microarray. II. Differentially expressed focus genes. Poult Sci. 2012;91(10):2576-87.

4. Bottje W, Kong BW. Cell Biology Symposium: feed efficiency: mitochondrial function to global gene expression. J Anim Sci. 2013;91(4):1582-1593.

5. Zhou N, Lee WR, Abasht B. Messenger RNA sequencing and pathway analysis provide novel insights into the biological basis of chickens' feed efficiency. BMC Genom. 2015;16(1):1-20.

6. Lee J, Karnuah AB, Rekaya R, Anthony NB, Aggrey SE. Transcriptomic analysis to elucidate the molecular mechanisms that underlie feed efficiency in meat-type chickens.Mol Genet Genom. 2015;290(5):1673-1682. 
7. Davis RV, Lamont SJ, Rothschild MF, Persia ME, Ashwell CM, Schmidt CJ. Transcriptome analysis of post-hatch breast muscle in legacy and modern broiler chickens reveals enrichment of several regulators of myogenic growth. PLoS One. 2015;10(3):e0122525.

8. Pampouille E, Hennequet-Antier C, Praud C, Juanchich A, Brionne A, Godet E, Bordeau T, Fagnoul F, Le Bihan-Duval E, Berri C. Differential expression and co-expression gene network analyses reveal molecular mechanisms and candidate biomarkers involved in breast muscle myopathies in chicken. Sci Rep. 2019;9(1):1-7.

9. Beauclercq S, Hennequet-Antier C, Praud C, Godet E, Collin A, Tesseraud S, Métayer-Coustard S, Bourin M, Moroldo M, Martins F, et al. Muscle transcriptome analysis reveals molecular pathways and biomarkers involved in extreme ultimate pH and meat defect occurrence in chicken. Sci Rep. 2017;7(1):1-3.

10. Jia X, Lin H, Nie Q, Zhang X, Lamont SJ. A short insertion mutation disrupts genesis of miR-16 and causes increased body weight in domesticated chicken. Sci Rep. 2016;6(1):1-1.

11. Sun Y, Huang Y, Hu G, Zhang X, Ruan Z, Zhao X, Guo C, Tang Z, Li X, You X, et al. Comparative transcriptomic study of muscle provides new insights into the growth superiority of a novel grouper hybrid. PLoS One. 2016;11(12):e0168802.

12. Schiaffino S, Mammucari C. Regulation of skeletal muscle growth by the IGF1-Akt/PKB pathway: insights from genetic models. Skelet Muscle. 2011;1(1):4.

13. Fuentes EN, Valdes JA, Molina A, Bjornsson BT. Regulation of skeletal muscle growth in fish by the growth hormone-insulin-like growth factor system. Gen Comp Endocrinol. 2013;192:136-148.

14. Rowe RW, Goldspink G. Muscle fibre growth in five different muscles in both sexes of mice. J Anat. 1969;104(3):519-530.

15. Rehfeldt C, Fiedler I, Dietl G, Ender K. Myogenesis and postnatal skeletal muscle cell growth as influenced by selection. Livest Prod Sci. 2000;66(2):177188.

16. Timson BF, Dudenhoeffer GA. Skeletal muscle fibre number in the rat from youth to adulthood. J Anat. 1990;173:33-36.

17. Stickland NC. Growth and development of muscle fibres in the rainbow trout (Salmo gairdneri). J Anat. 1983;137:323-333.

18. Weatherley A, Gill H, Lobo A. Recruitment and maximal diameter of axial muscle fibres in teleosts and their relationship to somatic growth and ultimate size. J Fish Biol. 1988;33(6):851-859.

19. Bhattacharya TK, Chatterjee RN, Dushyanth K, Shukla R. Cloning, characterization and expression of myostatin (growth differentiation factor-8) gene in broiler and layer chicken (Gallus gallus). Mol Biol Rep. 2015;42:319-327.

20. Bhattacharya TK, Shukla R, Chatterjee RN, Bhanja SK.Comparative analysis of silencing expression of myostatin (MSTN) and its two receptors (ACVR2A and ACVR2B) genes affecting growth traits in knock down chicken. Sci Rep. 2019;9:

21. Weatherley A, Gill H. Dynamics of increase in muscle fibers in fishes in relation to size and growth. Experientia. 1985;41(3):353-354.

22. Dorshorst BJ, Ashwell CM. Genetic mapping of the sex-linked barring gene in the chicken. Poult Sci. 2009;88(9):1811-1817.

23. Lopez G, de Lange K, Leeson S. Partitioning of retained energy in broilers and birds with intermediate growth rate. Poult Sci. 2007;86(10):2162-2171.

24. Silversides F, Villeneuve P. Ovarian follicular growth and maturity and follicular production of progesterone and oestradiol in response to porcine luteinising hormone and porcine follicle stimulating hormone in albino ( $\mathrm{S}^{*} \mathrm{AS}$ ) hens in vivo and in vitro. Br Poult Sci. 1999;40:545-551.

25. Ciacciariello M, Gous RA. comparison of the effects of feeding treatments and lighting on age at first egg and subsequent laying performance and carcase composition of broiler breeder hens. Br. Poult. Sci. 2005;46:246-254.

26. Kang B, Guo JR, Yang HM, Zhou RJ, Liu JX, Li SZ, Dong CY. Differential expression profiling of ovarian genes in prelaying and laying geese. Poult. Sci. 2009;88:1975-1983.

27. Luan X, Liu D, Cao Z, Luo L, Liu M, Gao M, Zhang X. Transcriptome Profiling Identifies Differentially Expressed Genes in Huoyan Goose Ovaries between the Laying Period and Ceased Period. PLoS One 2014;9:e113211.

28. Shiue YL, Chen LR, Chen CF, Chen YL, Ju JP, Chao CH, Lin YP, Kuo YM, Tang PC, Lee YP. Identification of transcripts related to high egg production in the chicken hypothalamus and pituitary gland. Theriogenology. 2006;66:1274-1283.

29. Wang C, Ma W. Hypothalamic and pituitary transcriptome profiling using RNA-sequencing in high-yielding and low-yielding laying hens. Sci. Rep. 2019;9:10285.

30. Eisen MB, Spellman PT, Brown PO, Botstein D. Cluster analysis and display of genome-wide expression patterns. Proc Natl Acad Sci USA. 1998;95:1486314868.

31. Huang DW, Sherman BT, Lempicki RA. Systematic and integrative analysis of large gene lists using DAVID bioinformatics resources. Nat Protoc. 2009a;4:44-57.

32. Huang DW, Sherman BT, Lempicki RA. Bioinformatics enrichment tools: paths toward the comprehensive functional analysis of large gene lists. Nucleic Acids Res. 2009b;37:1-13.

33. Vandesompele J, De Preter K, Pattyn F, Poppe B, Van Roy N, De Paepe A, Speleman F. Accurate normalization of real-time quantitative RT-PCR data by geometric averaging of multiple internal control genes. Genome Biol. 2002;3(7):1-2.

34. Andersen CL, Jensen JL, Ørntoft TF. Normalization of real-time quantitative reverse transcription-PCR data: a model-based variance estimation approach to identify genes suited for normalization, applied to bladder and colon cancer data sets. Cancer Res. 2004;64:5245-5250.

35. Pfaffl MW, Tichopad A, Prgomet C, Neuvians TP. Determination of stable housekeeping genes, differentially regulated target genes and sample integrity: BestKeeper-excel based tool using pair-wise correlations. Biotechnol Lett. 2004;26:509-515. 
36. Silver N, Best S, Jiang J, Thein SL. Selection of housekeeping genes for gene expression studies in human reticulocytes using real-time PCR. BMC Mol Biol. 2006;7(1):1-9.

37. Xie F, Xiao P, Chen D, Xu L, Zhang B. miRDeepFinder: a miRNA analysis tool for deep sequencing of plant small RNAs. Plant Mol Biol. 2012;80:75-84.

38. Bustin SA, Benes V, Garson JA, Hellemans J, Huggett J, Kubista M, Mueller R, Nolan T, Pfaffl MW, Shipley GL, et al. The MIQE guidelines: minimum information for publication of quantitative real-time PCR experiments. Clin Chem. 2009;55:611-622.

39. Bages S, Estany J, Tor M, Pena RN. Investigating reference genes for quantitative real-time PCR analysis across four chicken tissues. Gene. 2015;561:8287.

40. Nascimento CS, Barbosa LT, Brito C, Fernandes RP, Mann RS, Pinto AP, Oliveira HC, Dodson MV, Guimarães SE, Duarte MS. Identification of suitable reference genes for real time quantitative polymerase chain reaction assays on pectoralis major muscle in chicken (Gallus gallus). PLoS One. 2015;10(5):e0127935.

41. Olias P, Adam I, Meyer A, Scharff C, Gruber AD. Reference Genes for Quantitative Gene Expression Studies in Multiple Avian Species. PLoS One. 2014;9(6):e99678.

42. Borowska D, Rothwell L, Bailey RA, Watson K, Kaiser P. Identification of stable reference genes for quantitative PCR in cells derived from chicken lymphoid organs. Vet Immunol Immunopathol. 2016;170:20-24.

43. De Boever S, Vangestel C, De Backer P, Croubels S, Sys SU. Identification and validation of housekeeping genes as internal control for gene expression in an intravenous LPS inflammation model in chickens. Vet Immunol Immunopathol. 2008;122:312-317.

44. Yang F, Lei X, Rodriguez-Palacios A, Tang C, Yue H. Selection of reference genes for quantitative real-time PCR analysis in chicken embryo fibroblasts infected with avian leukosis virus subgroup. J BMC Res Notes. 2013;6:402.

45. Yue H, Xw Lei, FI Yang, Li MY, Tang C. Reference gene selection for normalization of PCR analysis in chicken embryo fibroblast infected with H5N1 AIV. Virol Sin. 2010;25:425-431.

46. Zhang J, Gao Y-Y, Huang Y-Q, Fan Q, Lu X-T, Wang C-K. Selection of housekeeping genes for quantitative gene expression analysis in yellow-feathered broilers. Ital J Anim Sci. 2018;17(2):540-546.

47. Khan S, Roberts J, Wu S. Reference gene selection for gene expression study in shell gland and spleen of laying hens challenged with infectious bronchitis virus. Sci Rep. 2017; 7:14271.

48. Mitra T, Bilic I, Hess M, Liebhart D. The 60S ribosomal protein L13 is the most preferable reference gene to investigate gene expression in selected organs from turkeys and chickens, in context of different infection models. Vet Res. 2016;47(1):105.

49. Exposito-Rodriguez M, Borges AA, Borges-Perez A, Perez JA. Selection of internal control genes for quantitative real-time RT-PCR studies during tomato development process. BMC Plant Biol. 2008;8:131.

50. Paolacci AR, Tanzarella OA, Porceddu E, Ciaffi M. Identification and validation of reference genes for quantitative RT-PCR normalization in wheat. BMC Mol Biol. 2009;10:11.

51. Hellemans J, Mortier G, Paepe AD, Speleman F, Vandesompele J. qBase relative quantification framework and software for management and automated analysis of real-time quantitative PCR data. Genome Biol. 2007;8(2):R19.

52. Chen HL. cDNA Cloning and Tissue Expression of TNNC1, TNNC2 and TNNT3 in Tianfu goat. Sichuan, China: Sichuan Agricultural University; 2012.

53. Zhang HQ. cDNA Cloning and Tissue Expression of TNNT1, TNNT2 and TNNI2 in Tianfu goat. Sichuan, China: Sichuan Agricultural University; 2014.

54. Dong CL. Multiscale Studies of Skeletal Muscle Contraction. Zhejiang, China: Zhejiang University; 2017.

55. Li DY, Ren WJ. Influence of exercise on the structure and function of myosin. Chinese J of Tissue Eng Res. 2007;11(32):6458-6464.

56. Chen L, Feng XC, Zhang YY, Liu XB, Zhang WG, Li CB, Ullah N, Xu XL, Zhou GH. Effects of ultrasonic processing on caspase-3, calpain expression and myofibrillar structure of chicken during post-mortem ageing. Food Chem. 2015a;177(12):280-287.

57. Zhao L, Xing T, Huang J, Qiao Y, Chen Y, Huang M. Involvement of $\mu / m$-calpain in the proteolysis and meat quality changes during postmortem storage of chicken breast muscle. Anim Sci J. 2018;89(2):423-431.

58. Liu SF. The Experimental Research of Annexin V, Vimentin and MYL3 Different Expression and Significance in Endometriosis with Blood Stasis Syndrome. Chengdu, China: Chengdu University of Traditional Chinese Medicine; 2013.

59. He YM, Gu MM. Research progress of myosin heavy chain genes in human genetic diseases. Yi Chuan. 2017;39(10):877-887.

60. Yuceyar N, Ayhan $€$ O, Karasoy H, Tolun A. Homozygous $€$ MYH7 R1820W mutation results in recessive myosin storage myopathy: Scapuloperoneal and respiratory weakness with dilated cardiomyopathy. Neuromuscul Disord. 2015;25(4):340-344.

61. Feinstein-Linial M, Buvoli M, Buvoli A, Sadeh M, Dabby R, Straussberg R, Shelef I, Dayan D, Leinwand LA, Birk OS. Two novel MYH7 proline substitutions cause Laing Distal Myopathy-like phenotypes with variable expressivity and neck extensor contracture. BMC Med Genet. 2016;17(1):1-9.

62. Zhang Z, Jiang X, Li Q, Yang Z, Qiu M, Jiang X, Liu L, Xia B, Xiong X. Differential expression of MYH7 gene in different tissues of chicken. China Poultry. 2016a;38(24):52-54.

63. Zhang C, Wang J, Wang G, Ji Z, Hou L, Liu Z, Chao T. Molecular cloning and mRNA expression analysis of sheep MYL3 and MYL4 genes. Gene. 2016b;577(2):209-214.

64. Zhang SZ, Xu Y, Xie HQ, Li XQ, Wei YQ, Yang ZM. The possible role of myosin light chain in myoblast proliferation. Biol Res. 2009;42(1):121-32.

65. Ouyang H, Wang Z, Chen X, Yu J, Li Z, Nie Q. Proteomic analysis of chicken skeletal muscle during embryonic development. Front Physiol. $2017 ; 8: 281$.

66. Cleveland BM, Evenhuis JP. Molecular characterization of atrogin-1/F-box protein-32 (FBXO32) and Fbox protein-25 (FBXO25) in rainbow trout (Oncorhynchus mykiss): expression across tissues in response to feed deprivation. Comp Biochem Physiol B, Biochem Mol Biol. 2010;157(3):248-257.

Page $13 / 27$ 
67. Bodine SC, Latres E, Baumhueter S, Lai VK, Nunez L, Clarke BA, Poueymirou WT, Panaro FJ, Na E, Dharmarajan K, et al. Identification of ubiquitin ligases required for skeletal muscle atrophy. Science. 2001;294(5547):1704-8.

68. Chen B, Xu J, He X, Xu H, Li G, Du H, Nie Q, Zhang X. A genome-wide mRNA screen and functional analysis reveal FOXO3 as a candidate gene for chicken growth. PLoS One. 2015b;10(9):e0137087.

69. Liu YY, Li LL, Xia X, Xue XD, Fu JH. Research progress on the correlation between tight junction proteins and lung diseases. J of Clin Ped. 2012;30(5):492495.

70. Zhang JW, Lin HJ, Han L. Research progress of intestinal epithelial tight junctions. China Medical Herald. 2015;12(6):160-163.

71. Hartsock A, Nelson WJ. Adherens and tight junctions: structure, function and connections to the actin cytoskeleton. Biochim Biophys Acta. 2008;1778(3):660-669.

72. Xue Q, Zhang G, Li T, Ling J, Zhang X, Wang J. Transcriptomic profile of leg muscle during early growth in chicken. PLoS One. 2017;12(3):e0173824.

73. Akizawa Y, Kanno H, Kawamichi Y, Matsuda Y, Ohta H, Fujii H, Matsui H, Saito K. Enhanced expression of myogenic differentiation factors and skeletal muscle proteins in human amnion-derived cells via the forced expression of MYOD1. Brain Dev. 2013;35(4):349-355.

74. Sartorelli V, Huang J, Hamamori Y, Kedes L. Molecular mechanisms of myogenic coactivation by p300: direct interaction with the activation domain of MyoD and with the MADS box of MEF2C. Mol Cell Biol. 1997;17:1010-1026.

75. Milewska M, Grabiec K, Grzelkowska-Kowalczyk K. Interactions of proliferation and differentiation signaling pathways in myogenesis. Postepy Hig Med Dosw. 2014;68:516-26.

76. Buckingham M, Rigby PW. Gene regulatory networks and transcriptional mechanisms that control myogenesis. Dev Cell. 2014;28:225-238.

77. Takada F, Vander Woude DL, Tong HQ, Thompson TG, Watkins SC, Kunkel LM, Beggs AH. Myozenin: an a-actinin-and Y-filamin-binding protein of skeletal muscle Z lines. Proc Natl Acad Sci USA. 2001;98(4):1595-1600.

78. Frey N, Richardson JA, Olson EN. Calsarcins, a novel family of sarcomeric calcineurin-binding proteins. Proc Natl Acad Sci USA. 2000;97:14632-14637.

79. Frey N, Frank D, Lippl S, Kuhn C, Kögler H, Barrientos T, Rohr C, Will R, Müller OJ, Weiler H, et al. Calsarcin-2 deficiency increases exercise capacity in mice through calcineurin/NFAT activation. J Clin Invest. 2008;118(11):3598-608.

80. Frey N, Barrientos T, Shelton JM, Frank D, Rütten H, Gehring D, Kuhn C, Lutz M, Rothermel B, Bassel-Duby R, et al. Mice lacking calsarcin-1 are sensitized to calcineurin signaling and show accelerated cardiomyopathy in response to pathological biomechanical stress. Nat Med. 2004;10(12):1336-43.

81. Schulz RA, Yutzey KE. Calcineurin signaling and NFAT activation in cardiovascular and skeletal muscle development. Dev Biol. 2004;266:1-16.

82. Lewis TS, Shapiro PS, Ahn NG. Signal transduction through MAP kinase cascades. Adv Cancer Res. 1998;74:49-139.

83. Errede B, Cade RM, Yashar BM, Kamada Y, Levin DE, Irie K, Matsumoto K. Dynamics and organization of MAP kinase signal pathways. Mol Reprod Dev. 1995;42:477-485.

84. Gustin MC, Albertyn J, Alexander M, Davenport K. MAP kinase pathways in the yeast Saccharomyces cerevisiae. Microbiol Mol Biol Rev. 1998;62:12641300.

85. Davis RJ. Signal transduction by the JNK group of MAP kinases. Inflammatory Processes. 2000;13-21.

86. Raingeaud J, Whitmarsh AJ, Barrett T, Derijard B, Davis RJ. MKK3-and MKK6-regulated gene expression is mediated by the p38 mitogen-activated protein kinase signal transduction pathway. Mol Cell Biol. 1996;16(3):1247-1255.

87. Ninomiya-Tsuji J, Kishimoto K, Hiyama A, Inoue JI, Cao Z, Matsumoto K. The kinase TAK1 can activate the NIK-IKB as well as the MAP kinase cascade in the IL-1 signalling pathway. Nature. 1999;398(6724):252-256.

88. Kong BW, Lassiter K, Piekarski-Welsher A, Dridi S, Reverter-Gomez A, Hudson NJ, Bottje WG. Proteomics of breast muscle tissue associated with the phenotypic expression of feed efficiency within a pedigree male broiler line: I. Highlight on mitochondria. PLoS One. 2016;11(5):e0155679.

89. Biederer C, Ries S, Drobnik W, Schmitz G. Molecular cloning of human caveolin 3. Biochim Biophys Acta (BBA)-Molecular Basis of Disease. 1998;1406(1):5-9.

90. Woodman SE, Sotgia F, Galbiati F, Minetti C, Lisanti MP. Caveolinopathies: mutations in caveolin-3 cause four distinct autosomal dominant muscle diseases. Neurology. 2004;62(4):538-543.

91. Zhu Z, Li Y, Mo D, Li K, Zhao S. Molecular characterization and expression analysis of the porcine caveolin-3 gene. Biochem Biophys Res. 2006;346(1):713.

92. Smythe GM, Rando TA. Altered caveolin-3 expression disrupts PI (3) kinase signaling leading to death of cultured muscle cells. Exp Cell Res. 2006;312(15):2816-25.

93. Bottje WG, Carstens GE. Association of mitochondrial function and feed efficiency in poultry and livestock species. J Anim Sci. 2009;87(suppl_14):E48E63.

94. Senf SM, Howard TM, Ahn B, Ferreira LF, Judge AR. Loss of the inducible Hsp70 delays the inflammatory response to skeletal muscle injury and severely impairs muscle regeneration. PLoS One. 2013;8(4):e62687.

95. Truscott KN, Brandner K, Pfanner N. Mechanisms of protein import into mitochondria. Curr Biol. 2003;13(8):R326-R337.

96. Herrmann JM, Stuart RA, Craig EA, Neupert W. Mitochondrial heat shock protein 70, a molecular chaperone for proteins encoded by mitochondrial DNA. J Cell Biol. 1994;127(4):893-902.

97. Ferreira LF, Laitano O. Regulation of NADPH oxidases in skeletal muscle. Free Radic Biol Med. 2016;98:18-28.

98. Dikalov S. Cross talk between mitochondria and NADPH oxidases. Free Radic Biol Med. 2011;51(7):1289-1301. 
99. Kobayashi A, Kang MI, Okawa H, Ohtsuji M, Zenke Y, Chiba T, Igarashi K, Yamamoto M. Oxidative stress sensor Keap1 functions as an adaptor for Cul3based E3 ligase to regulate proteasomal degradation of Nrf2. Mol Cell Biol. 2004;24(16):7130-7139.

100. Kobayashi A, Kang MI, Watai Y, Tong KI, Shibata T, Uchida K, Yamamoto M. Oxidative and electrophilic stresses activate Nrf2 through inhibition of ubiquitination activity of Keap1. Mol Cell Biol. 2006;26(1):221-229.

101. McPherron AC, Lawler AM, Lee SJ. Regulation of skeletal muscle mass in mice by a new TGF-p superfamily member. Nature. 1997;387(6628):83-90.

102. Lee S-J, McPherron AC. Regulation of myostatin activity and muscle growth. Proc Natl Acad Sci USA. 2001;98(16):9306-9311.

103. Lee SJ, Reed LA, Davies MV, Girgenrath S, Goad ME, Tomkinson KN, Wright JF, Barker C, Ehrmantraut G, Holmstrom J, et al. Regulation of muscle growth by multiple ligands signaling through activin type II receptors. Proc Natl Acad Sci USA. 2005;102(50):18117-22.

104. Han HQ, Mitch WE. Targeting the myostatin signaling pathway to treat muscle wasting diseases. Curr Opin Support Palliat Care. 2011;5(4):334-341.

105. Lee SJ, Glass DJ. Treating cancer cachexia to treat cancer. Skelet muscle. 2011;1(1):1-5.

106. Elkina Y, von Haehling S, Anker SD, Springer J. The role of myostatin in muscle wasting: an overview. J Cachexia Sarcopenia Muscle. $2011 ; 2(3): 143-151$.

107. Lassiter K, Kong BC, Piekarski-Welsher A, Dridi S, Bottje WG. Gene Expression Essential for Myostatin Signaling and Skeletal Muscle Development Is Associated with Divergent Feed Efficiency in Pedigree Male Broilers. Front Physiol. 2019;10:126.

108. Morissette MR, Cook SA, Foo S, McKoy G, Ashida N, Novikov M, Scherrer-Crosbie M, Li L, Matsui T, Brooks G, et al. Myostatin regulates cardiomyocyte growth through modulation of Akt signaling. Circ Res. 2006;99(1):15-24.

109. Sharma M, Kambadur R, Matthews KG, Somers WG, Devlin GP, Conaglen JV, Fowke PJ, Bass JJ. Myostatin, a transforming growth factor- $\beta$ superfamily member, is expressed in heart muscle and is upregulated in cardiomyocytes after infarct. J Cell Physiol. 1999;180(1):1-9.

110. Shyu KG, Lu MJ, Wang BW, Sun HY, Chang H. Myostatin expression in ventricular myocardium in a rat model of volume-overload heart failure. European journal of clinical investigation. 2006;36(10):713-719.

111. Allen DL, Cleary AS, Speaker KJ, Lindsay SF, Uyenishi J, Reed JM, Madden MC, Mehan RS. Myostatin, activin receptor Ilb, and follistatin-like-3 gene expression are altered in adipose tissue and skeletal muscle of obese mice. American Journal of Physiology-Endocrinology and Metabolism. 2008;294(5):E918-E927.

112. Ji S, Losinski RL, Cornelius SG, Frank GR, Willis GM, Gerrard DE, Depreux FF, Spurlock ME. Myostatin expression in porcine tissues: tissue specificity and developmental and postnatal regulation. Am J Physiol Regul Integr Comp. 1998;275(4):R1265-R1273.

113. McFarland DC, Velleman SG, Pesall JE, Liu C. Effect of myostatin on turkey myogenic satellite cells and embryonic myoblasts. Comp. Biochem. Physiol. A Mol. Integr. Physiol. 2006;144(4):501-508.

114. Gu Z, Zhu D, Li N, Li H, Deng X, Wu C. The single nucleotide polymorphisms of the chicken myostatin gene are associated with skeletal muscle and adipose growth. Sci. China Life Sci. 2004;47(1):25-30.

115. Ye X, Brown SR, Nones K, Coutinho LL, Dekkers JC, Lamont SJ. Associations of myostatin gene polymorphisms with performance and mortality traits in broiler chickens. Genet. Sel. Evol. 2007;39(1):1-7.

116. Bhattacharya TK, Chatterjee RN. Polymorphism of the myostatin gene and its association with growth traits in chicken. Poult Sci. 2013;92(4):910-915.

117. Hu S, Ni W, Sai W, Zi H, Qiao J, Wang P, Sheng J, Chen C. Knockdown of myostatin expression by RNAi enhances muscle growth in transgenic sheep. PLoS One. 2013;8(3):e58521.

118. Tripathi AK, Aparnathi MK, Vyavahare SS, Ramani UV, Rank DN, Joshi CG. Myostatin gene silencing by RNA interference in chicken embryo fibroblast cells. J Biotechnol. 2012;160(3-4):140-5.

119. Sylva M, Moorman AF, van den Hof MJ. Follistatin-like 1 in vertebrate development. Birth Defects Res Embryo Today. 2013;99(1):61-69.

120. Adams D, Larman B, Oxburgh L. Developmental expression of mouse Follistatin-like 1 (Fstl1): dynamic regulation during organogenesis of the kidney and lung. Gene Expr Patterns. 2007;7(4):491-500.

121. Wu Y, Zhou S, Smas CM. Downregulated expression of the secreted glycoprotein follistatin-like 1 (Fstl1) is a robust hallmark of preadipocyte to adipocyte conversion. Mech Dev. 2010;127(3-4):183-202.

122. Ten Dijke P, Ichijo H, Franzén P, Schulz P, Saras J, Toyoshima H, Heldin CH, Miyazono K. Activin receptor-like kinases: a novel subclass of cell-surface receptors with predicted serine/threonine kinase activity. Oncogene. 1993;8(10):2879-2887.

123. Inman GJ, Nicolás FJ, Hill CS. Nucleocytoplasmic shuttling of Smads 2, 3, and 4 permits sensing of TGF- $\beta$ receptor activity. Mol Cell. 2002;10(2):283-294.

124. Harrison CA, Gray PC, Koerber SC, Fischer W, Vale W. Identification of a functional binding site for activin on the type I receptor ALK4. J Biol Chem. 2003;278(23):21129-1135.

125. Doré JJ, Edens M, Garamszegi N, Leof EB. Heteromeric and homomeric transforming growth factor-beta receptors show distinct signaling and endocytic responses in epithelial cells. J Biol Chem. 1998;273(48):31770-31777.

126. Dickinson ME, Kobrin MS, Silan CM, Kingsley DM, Justice MJ, Miller DA, Ceci JD, Lock LF, Lee A, Buchberg AM. Chromosomal localization of seven members of the murine TGF-beta superfamily suggests close linkage to several morphogenetic mutantloci. Genomics. 1990;6:505-520.

127. Derynck R, Zhang Y, Feng XH. Smads: transcriptional activators of TGF-beta responses. Cell. 1998;95(6):737-40.

128. Massagué J, Seoane J, Wotton D. Smad transcription factors. Genes Dev. 2005;19(23):2783-810.

129. Wu JW, Hu M, Chai J, Seoane J, Huse M, Li C, Rigotti DJ, Kyin S, Muir TW, Fairman R, et al. Crystal structure of a phosphorylated Smad2. Recognition of phosphoserine by the MH2 domain and insights on Smad function in TGF-beta signaling. Mol Cell.2001;8(6):1277-1289.

130. Massagué J. TGF $\beta$ signalling in context. Nat Rev Mol. 2012;13(10):616-630. 
131. Shi Y, Hata A, Lo RS, Massagué J, Pavletich NP. A structural basis for mutational inactivation of the tumour suppressor Smad4. Nature. 1997;388(6637):87-93.

132. Macias MJ, Martin-Malpartida P, Massagué J. Structural determinants of Smad function in TGF- $\beta$ signaling. Trends Biochem Sci. 2015;40(6):296-308.

133. Itoh F, Asao H, Sugamura K, Heldin CH, ten Dijke P, Itoh S (August 2001). "Promoting bone morphogenetic protein signaling through negative regulation of inhibitory Smads". EMBO J. 2001;20(15):4132-4142.

134. Yan X, Liao H, Cheng M, Shi X, Lin X, Feng XH, Chen YG. Smad7 Protein Interacts with Receptor-regulated Smads (R-Smads) to Inhibit Transforming Growth Factor- $\beta$ (TGF- $\beta$ )/Smad Signaling. J Biol Chem. 2016;291(1):382-392.

135. Hardie DG, Carling D, Carlson M. The AMP-activated/SNF1 protein kinase subfamily: metabolic sensors of the eukaryotic cell? Annu Rev Biochem. 1998;67:821-855.

136. Viollet B, Andreelli F, Jørgensen SB, Perrin C, Flamez D, Mu J, Wojtaszewski JF, Schuit FC, Birnbaum M, Richter E, et al. Physiological role of AMP-activated protein kinase (AMPK): insights from knockout mouse models. Biochem Soc Trans. 2003a;31(1):216-219.

137. Viollet B, Andreelli F, Jørgensen SB, Perrin C, Geloen A, Flamez D, Mu J, Lenzner C, Baud O, Bennoun M, et al. The AMP-activated protein kinase a2 catalytic subunit controls whole-body insulin sensitivity. J Clin Invest. 2003b;111(1):91-98.

138. Fu X, Zhao JX, Liang J, Zhu MJ, Foretz M, Viollet B, Du M. AMP-activated protein kinase mediates myogenin expression and myogenesis via histone deacetylase 5. Am J Physiol Cell Physiol. 2013;305(8):C887-895.

139. Zhou G, Myers R, Li Y, Chen Y, Shen X, Fenyk-Melody J, Wu M, Ventre J, Doebber T, Fujii N, et al. Role of AMP-activated protein kinase in mechanism of metformin action. J Clin Investig. 2001;108(8):1167-1174.

140. Hardie DG, Scott JW, Pan DA, Hudson ER. Management of cellular energy by the AMP-activated protein kinase system. FEBS Lett. 2003;546(1):113-120.

141. Carling D. The AMP-activated protein kinase cascade-a unifying system for energy control. Trends in biochemical sciences. 2004;29(1):18-24.

142. Bottje W, Kong BW, Reverter A, Waardenberg AJ, Lassiter K, Hudson NJ. Progesterone signalling in broiler skeletal muscle is associated with divergent feed efficiency. BMC Syst Biol. 2017a;11(1):1-6.

143. Bottje WG, Lassiter K, Dridi S, Hudson N, Kong BW. Enhanced expression of proteins involved in energy production and transfer in breast muscle of pedigree male broilers exhibiting high feed efficiency. Poult Sci.2017b;96(7):2454-2458.

144. De Palma C, Morisi F, Pambianco S, Assi E, Touvier T, Russo S, Perrotta C, Romanello V, Carnio S, Cappello V, et al. Deficient nitric oxide signalling impairs skeletal muscle growth and performance: involvement of mitochondrial dysregulation. Skelet Muscle. 2014;4(1):1-21.

145. Nisoli E, Clementi E, Paolucci C, Cozzi V, Tonello C, Sciorati C, Bracale R, Valerio A, Francolini M, Moncada S, et al. Mitochondrial biogenesis in mammals: the role of endogenous nitric oxide. Science. 2003;299(5608):896-899.

146. Marziano V, Pugliese A, Merler S, Ajelli M. Detecting a surprisingly low transmission distance in the early phase of the 2009 influenza pandemic. Sci Rep. 2017;7(1):1-9.

147. Rajkumar U, Muthukumar M, Haunshi S, Niranjan M, Raju MV, Rama Rao SV, Chatterjee RN. Comparative evaluation of carcass traits and meat quality in native Aseel chickens and commercial broilers. Br Poult Sci. 2016;57(3):339-347.

148. Beauclercq S, Hennequet-Antier C, Praud C, Godet E, Collin A, Tesseraud S, Métayer-Coustard S, Bourin M, Moroldo M, Martins F, et al. Muscle transcriptome analysis reveals molecular pathways and biomarkers involved in extreme ultimate $\mathrm{pH}$ and meat defect occurrence in chicken. Sci Rep. 2017;7(1):1-3.

149. Beauclercq S, Nadal-Desbarats L, Hennequet-Antier C, Collin A, Tesseraud S, Bourin M, Le Bihan-Duval E, Berri C. Serum and muscle metabolomics for the prediction of ultimate $\mathrm{pH}$, a key factor for chicken-meat quality. J Proteome Res. 2016;15(4):1168-1178.

150. Cheung PC, Salt IP, Davies SP, Hardie DG, Carling D. Characterization of AMP-activated protein kinase Y-subunit isoforms and their role in AMP binding. Biochem J. 2000;346(3):659-669.

151. Laplante M, Sabatini DM. Regulation of mTORC1 and its impact on gene expression at a glance. J Cell Sci. 2013;126(8):1713-1719.

152. Bottje WG, Kong BW, Lee JY, Washington T, Baum J, Dridi S, Wing T, Hardiman J. Potential roles of mTOR and protein degradation pathways in the phenotypic expression of feed efficiency in broilers. Biochem Physiol. 2014;3(125):2.

153. Schiaffino S, Dyar KA, Ciciliot S, Blaauw B, Sandri M. Mechanisms regulating skeletal muscle growth and atrophy. FEBS J. 2013;280(17):4294-4314.

154. Kim DH, Sarbassov DD, Ali SM, King JE, Latek RR, Erdjument-Bromage H, Tempst P, Sabatini DM. mTOR interacts with raptor to form a nutrient-sensitive complex that signals to the cell growth machinery. Cell. 2002;110(2):163-175.

155. Bigot K, Taouis M, Tesseraud S. Refeeding and insulin regulate S6K1 activity in chicken skeletal muscles. J Nutr. 2003;133(2):369-373.

156. Bottje WG, Lassiter K, Piekarski-Welsher A, Dridi S, Reverter A, Hudson NJ, Kong BW. Proteogenomics reveals enriched ribosome assembly and protein translation in pectoralis major of high feed efficiency pedigree broiler males. Front Physiol. 2017c;8:306.

157. Dupont J, Derouet M, Simon J, Taouis M. Effect of nutritional state on the formation of a complex involving insulin receptor IRS-1, the 52 kDa Src homology/collagen protein (Shc) isoform and phosphatidylinositol 3'-kinase activity. Biochem J. 1998a;335(2):293-300.

158. Dupont J, Derouet M, Simon J, Taouis M. Nutritional state regulates insulin receptor and IRS-1 phosphorylation and expression in chicken. Am J Physiol Endocrinol Metab. 1998b;274(2):E309-E316.

159. Florini JR, Magri K, Ewton D, James P, Grindstaff K, Rotwein P. Spontaneous differentiation of skeletal myoblasts is dependent upon autocrine secretion of insulin-like growth factor. J Biol Chem. 1991a;266:15917-15923.

160. Florini JR, Magri KA. Effects of growth factors on myogenic differentiation. Am J Physiol. 1989;256:C701-C711.

161. Florini JR, Ewton DZ, Magri KA. Hormones, growth factors, and myogenic differentiation. Annu Rev Physiol. 1991b;53:201-216.

Page $16 / 27$ 
162. Florini JR, Ewton DZ, Falen SL, Van Wyk JJ. Biphasic concentration dependency of stimulation of myoblast differentiation by somatomedins. Am J Physiol. 1986;19:C771-C778.

163. Stewart CE, Rotwein P. Growth, differentiation, and survival: multiple physiological functions for insulin-like growth factors. Physiol Rev. 1996;76(4):10051026.

164. Spangenburg EE, Abraha T, Childs TE, Pattison JS, Booth FW. Skeletal muscle IGF-binding protein-3 and-5 expressions are age, muscle, and load dependent. Am J Physiol Endocrinol Metab. 2003;284(2):E340-E350.

165. Foulstone EJ, Savage PB, Crown AL, Holly JM, Stewart CE. Role of insulin-like growth factor binding protein-3 (IGFBP-3) in the differentiation of primary human adult skeletal myoblasts. J Cell Physiol. 2003;195(1):70-79.

166. Weyman CM, Wolfman A. Mitogen-Activated Protein Kinase Kinase (MEK) activity is required for inhibition of skeletal muscle differentiation by InsulinLike Growth Factor 1 or Fibroblast Growth Factor 21. Endocrinology. 1998;139(4),1794-1800.

167. Roulin A. The evolution, maintenance and adaptive function of genetic colour polymorphism in birds. Biol Rev. 2004;79:815-848.

168. Plonka PM, Passeron T, Brenner M, Tobin DJ, Shibahara S, Thomas A, Slominski A, Kadekaro AL, Hershkovitz D, Peters E, Nordlund JJ. What are melanocytes really doing all day long...?. Exp Dermatol. 2009;18(9):799-819.

169. Lee S-i, Kim M, Choe JC, Jablonski PG. Evolution of plumage coloration in the crow family (Corvidae) with a focus on the color-producing microstructures in the feathers: a comparison of eight species. Anim Cells and Syst. 2016;20:95-102.

170. Muroya S, Tanabe R, Nakajima I, Chikuni K. Molecular characteristics and site specific distribution of the pigment of the silky fowl. J Vet Med Sci. 2000;62:391-395.

171. Lin SJ, Foley J, Jiang TX, Yeh CY, Wu P, Foley A, Yen CM, Huang YC, Cheng HC, Chen CF. Topology of feather melanocyte progenitor niche allows complex pigment patterns to emerge. Science. 2013;340:1442-1445.

172. Yu S, Wang G, Liao J, Tang M, Sun W. Transcriptome profile analysis of mechanisms of black and white plumage determination in black-bone chicken. Cell Physiol Biochem. 2018;46(6):2373-2384.

173. Zhang J, Liu F, Cao J, Liu X. Skin transcriptome profiles associated with skin color in chickens. PLoS One. 2015a;10:e0127301.

174. Zhang XD, Wang HH, Zhang CX, Li QH, Chen XH, Lou LF. Analysis of skin color change and related gene expression after crossing of Dongxiang black chicken and ISA layer. Genet Mol Res. 2015b;14:11551-11561.

175. Duffy DL, Zhao ZZ, Sturm RA, Hayward NK, Martin NG, Montgomery GW. Multiple pigmentation gene polymorphisms account for a substantial proportion of risk of cutaneous malignant melanoma. J Invest Dermatol. 2010;130(2):520-528.

176. Nan H, Kraft P, Hunter DJ, Han J. Genetic variants in pigmentation genes, pigmentary phenotypes, and risk of skin cancer in Caucasians. Int $\mathrm{J}$ Cancer. 2009;125(4):909-917.

177. Sulem P, Gudbjartsson DF, Stacey SN, Helgason A, Rafnar T, Magnusson KP, Manolescu A, Karason A, Palsson A, Thorleifsson G, Jakobsdottir M. Genetic determinants of hair, eye and skin pigmentation in Europeans. Nat Genet. 2007;39(12):1443-1452.

178. Godwin AR, Capecchi MR. Hair defects in Hoxc13 mutant mice. J Invest Derm Symp P. 1999;4:244-247.

179. Chuong CM, Oliver G, Ting SA, Jegalian BG, Chen HM, De Robertis EM. Gradients of homeoproteins in developing feather buds. Development. 1990;110:1021-1030.

180. Awgulewitsch A. Hox in hair growth and development. Sci Nat. 2003;90:193-211.

181. Kanzler B, Viallet JP, Le MH, Boncinelli E, Duboule D, Dhouailly D. Differential expression of two different homeobox gene families during mouse tegument morphogenesis. Int J Dev Biol. 1994;38:633-640.

182. Stelnicki EJ, Kömüves LG, Kwong AO, Holmes D, Klein P, Rozenfeld S, Lawrence HJ, Adzick NS, Harrison M, Largman C. HOX Homeobox Genes Exhibit Spatial and Temporal Changes in Expression During Human Skin Development. J Invest Dermatol. 1998;110:110-115.

183. Packer Al, Jane-Wit D, Mclean L, Panteleyev AA, Christiano AM, Wolgemuth DJ. Hoxa4 expression in developing mouse hair follicles and skin. Mech Develop. 2000;99:153-157.

184. Widelitz RB. Wnt signaling in skin organogenesis. Organogenesis. 2008;4:123-133.

185. Cho M, Ryu M, Jeong Y, Chung Y-H, Kim D-E, Cho H-S, Kang S, Han J-S, Chang M-Y, Lee C-K, Jin M, Kim H-J, Oh S. Cardamonin suppresses melanogenesis by inhibition of Wnt/ $\beta$-catenin signaling. Biochem Bioph Res Co. 2009;390:500-505.

186. Yuji Yamaguchi SI, Hidenori Watabe, Ken-ichi Yasumoto, Zalfa A. Abdel-Malek, Tateki Kubo, François Rouzaud, Atsushi Tanemura, Kunihiko Yoshikawa, Vincent J. Hearing: Mesenchymal-epithelial interactions in the skin: increased expression of dickkopf1 by palmoplantar fibroblasts inhibits melanocyte growth and differentiation. J Cell Biol. 2004;165:275-285.

187. Yamaguchi Y, Passeron T, Watabe H, Yasumoto K, Rouzaud F, Hoashi T, Hearing VJ. The effects of dickkopf 1 on gene expression and Wnt signaling by melanocytes: mechanisms underlying its suppression of melanocyte function and proliferation. J Invest Dermatol. 2007;127:1217-1225.

188. Nguyen DX, Chiang AC, Zhang XH, Kim JY, Kris MG, Ladanyi M, Gerald WL, Massagué J. WNT/TCF signaling through LEF1 and HOXB9 mediates lung adenocarcinoma metastasis. Cell. 2009;138:51-62.

189. Kanzler B, Prin F, Thelu J, Dhouailly D. CHOXC-8 and CHOXD-13 expression in embryonic chick skin and cutaneous appendage specification. Dev Dynam. 1997;210:274-287.

190. Meister A. Selective modification of glutathione metabolism. Science. 1983;220:472-477.

191. Galván I, Alonso-Alvarez C. An Intracellular Antioxidant Determines the Expression of a Melanin-Based Signal in a Bird. PLoS One. 2008;3:e3335.

192. Ito S, Palumbo A, Prota G. Tyrosinase-cytalyzed conjugation of dopa with glutathione. Experientia. 1985;41:960-961.

Page $17 / 27$ 
193. Halprin KM, Ohkawara A. Glutathione and human pigmentation. Arch Dermatol. 1966;94:355-357.

194. Meyskens FL, Farmer P, Fruehauf JP. Redox Regulation in Human Melanocytes and Melanoma. Pigment Cell Res. 2001;14:148-154.

195. Benedetto JP, Ortonne JP, Voulot C, Khatchadourian C, Prota G, Thivolet J. Role of thiol compounds in mammalian melanin pigmentation: Part I. Reduced and oxidized glutathione. J Invest Dermatol. 1981;77:402-405.

196. Kumar A, Tikoo S, Maity S, Sengupta S, Kaur A, Bachhawat AK. Mammalian proapoptotic factor ChaC1 and its homologues function as Y-glutamyl cyclotransferases acting specifically on glutathione. EMBO Rep. 2012;13:1095-1101.

197. Crawford RR, Prescott ET, Sylvester CF, Higdon AN, Shan J, Kilberg MS, Mungrue IN. Human CHAC1 Protein Degrades Glutathione, and mRNA Induction Is Regulated by the Transcription Factors ATF4 and ATF3 and a Bipartite ATF/CRE Regulatory Element. J Biol Chem. 2015;290:15878-15891.

198. Benathan M. Opposite regulation of tyrosinase and glutathione peroxidase by intracellular thiols in human melanoma cells. Arch Dermatol Res. 1997;289:341-346.

199. Benathan M, Virador V, Furumura M, Kobayashi N, Panizzon RG, Hearing VJ. Co-regulation of melanin precursors and tyrosinase in human pigment cells: roles of cysteine and glutathione. Cell Mol Biol. 1999;45:981-990.

200. Kishi H, Kuroda E, Mishima HK, Yamashita U. Role of TGF-beta in the retinoic acid-induced inhibition of proliferation and melanin synthesis in chick retinal pigment epithelial cells in vitro. Cell Biol Int. 2001;25:1125-1129.

201. Divya D, Bhattacharya TK, Prakash MG, Chatterjee RN, Shukla R, Vishnu PB, Vinoth A, Dushyanth K. Molecular characterization and expression profiling of BMP 3 gene in broiler and layer chicken. Mol Biol Rep. 2018a;45(4):477-495.

202. Divya D, Prakash MG, Chatterjee RN, Reddy VR, Reddy YN, Bhattacharya TK. Relative Expression Profile of AA Genotype of BMP4 Gene in Broiler and Layer Chicken. J Anim Res. 2018b;8(4):549-554.

203. Moisá SJ, Shike DW, Graugnard DE, Rodriguezzas SL, Everts RE, Lewin HA, Faulkner DB, Berger LL, Loor JJ. Bioinformatics analysis of transcriptome dynamics during growth in angus cattle longissimus muscle. Bioinform Biol Insights. 2013;7:253-270.

204. Parvez S, Kang MK, Chung HS, Cho CW, Hong MC, Shin MK, Bae H. Survey and mechanism of skin depigmenting and lightening agents. Phytother Res. 2006;20(11):921-934.

205. Olivares C, Solano F. New insights into the active site structure and catalytic mechanism of tyrosinase and its related proteins. Pigm Cell Melanoma R. 2009;22(6):750-760.

206. Norris BJ, Whan VA. A gene duplication affecting expression of the ovine ASIP gene is responsible for white and black sheep. Genome Res. 2008;18(8):1282-1293.

207. Fan R, Xie J, Bai J, Wang H, Tian X, Bai R, Jia X, Yang L, Song Y, Herrid M, et al. Skin transcriptome profiles associated with coat color in sheep. BMC Genom. 2013;14(1):1-2.

208. Yang YJ, Zhao R, He XY, Li LP, Wang KW, Zhao L, Tu M, Tang JS, Xie ZG, Zhu YM. A novel splicing mutation of KIT results in piebaldism and auburn hair color in a Chinese family. Biomed Res Int. 2013;2013.

209. Yamada T, Hasegawa S, Inoue Y, Date Y, Yamamoto N, Mizutani H, Nakata S, Matsunaga K, Akamatsu H. Wnt/ $\beta$-catenin and kit signaling sequentially regulate melanocyte stem cell differentiation in UVB-induced epidermal pigmentation. J Invest Dermatol. 2013;133(12):2753-1262.

210. Minvielle F, Bed'hom B, Coville JL, Ito S, Inoue-Murayama M, Gourichon D. The "silver" Japanese quail and the MITF gene: causal mutation, associated traits and homology with the "blue" chicken plumage. BMC Genetics. 2010;11(1):1-7.

211. Saravanperumal SA, Pediconi D, Renieri C, La Terza A. Alternative splicing of the sheep MITF gene:Novel transcripts detectable in skin. Gene. 2014;552(1):165-175.

212. Li S, Wang C, Yu W, Zhao S, Gong Y. Identification of Genes Related to White and Black Plumage Formation by RNA-Seq from White and Black Feather Bulbs in Ducks. PLoS One. 2012;7:e36592.

213. Solano F, Briganti S, Picardo M, Ghanem G. Hypopigmenting agents: an updated review on biological, chemical and clinical aspects. Pigment Cell Res. 2006;19(6):550-571.

214. Schaffler A, Scholmerich J, Buechler C. The role of 'adipotropins' and the clinical importance of a potential hypothalamic-pituitary-adipose axis. Nat Clin Pract Endocrinol Metab. 2006;2(7):374-383.

215. Lalueza-Fox C, Römpler H, Caramelli D, Stäubert C, Catalano G, Hughes D, Rohland N, Pilli E, Longo L, Condemi S, et al. A melanocortin 1 receptor allele suggests varying pigmentation among Neanderthals. Science. 2007;318(5855):1453-1455.

216. Roberts DW, Newton RA, Beaumont KA, Helen Leonard J, Sturm RA. Quantitative analysis of MC1R gene expression in human skin cell cultures. Pigment Cell Res. 2006;19(1):76-89.

217. Drogemuller C, Giese A, Martins-Wess F, Wiedemann S, Andersson L, Brenig B, fries R, Leeb T. The mutation causing the black-and-tan pigmentation phenotype of Mangalitza pigs maps to the porcine ASIP locus but does not affect its coding sequence. Mamm Genome. 2006;17(1):58-66.

218. Liu H, Luo Q, Zhang J, Mo C, Wang Y, Li J. Endothelins (EDN1, EDN2, EDN3) and their receptors (EDNRA, EDNRB, EDNRB2) in chickens: Functional analysis and tissue distribution. General and comparative endocrinology. 2019;283:113231.

219. Dorshorst B, Molin AM, Rubin CJ, Johansson AM, Strömstedt L, Pham MH, Chen CF, Hallböök F, Ashwell C, Andersson L. A complex genomic rearrangement involving the endothelin 3 locus causes dermal hyperpigmentation in the chicken. PLoS Genet. 2011;7(12):e1002412.

220. Bain MM, Nys Y, Dunn IC. Increasing persistency in lay and stabilising egg quality in longer laying cycles. What are the challenges?. Br Poult Sci. 2016;57:330-338. 
221. Mishra SK, Chen B, Zhu Q, Xu Z, Ning C, Yin H, Wang Y, Zhao X, Fan X, Yang M, et al. Transcriptome analysis reveals differentially expressed genes associated with high rates of egg production in chicken hypothalamic-pituitary-ovarian axis. Sci Rep. 2020;10(1):1-8.

222. Reddy IJ, David CG, Sarma PV, Singh K. The possible role of prolactin in laying performance and steroid hormone secretion in domestic hen (Gallus domesticus). Gen. Comp. Endocrinol. 2002;127:249-255.

223. Talbot RT, Hanks MC, Sterling RJ, Sang HM, Sharp PJ. Pituitary prolactin messenger ribonucleic acid levels in incubating and laying hens: effects of manipulating plasma levels of vasoactive intestinal polypeptide. Endocrinology. 1991;129:496-502.

224. Han C, An G, Du X. Three novel single nucleotide polymorphisms of the 3-hydroxy-3-methylglutaryl coenzyme A reductase gene associated with eggproduction in chicken. Folia Biol. 2014;62:203-209.

225. Deeley, R. G., Tam, S. P. \& Archer, T. K. The effects of estrogen on apolipoprotein synthesis. Can. J. Biochem. Cell Biol. 63, $882-889$ (1985).

226. Nys, Y. \& Guyot, N. Egg formation and chemistry. In Improving the safety and quality of eggs and egg products Woodhead Publishing $83-132$ (2011).

227. Jeong W, Lim W, Kim J, Ahn SE, Lee HC, Jeong JW, Han JY, Song G, Bazer FW. Cell-specic and temporal aspects of gene expression in the chicken oviduct at different stages of the laying cycle. Biol Reprod. 2012;6(86):172.

228. Yang J, Li XY, Cao YH, Pokharel K, Hu XJ, Chen ZH, Xu SS, Peippo J, Honkatukia M, Kantanen J, et al. Comparative mRNA and miRNA expression in European mouon (Ovis musimon) and sheep (Ovis aries) provides novel insights into the genetic mechanisms for female reproductive success. Heredity. 2019;2(122):172-186.

229. Dong X, Li J, Zhang Y, Han D, Hua G, Wang J, Deng X, Wu C. Genomic Analysis Reveals Pleiotropic Alleles at EDN3 and BMP7 Involved in Chicken Comb Color and Egg Production. Frontiers in genetics 2019(10):612.

230. Stapane L, Le Roy N, Hincke MT, Gautron J. The glycoproteins EDIL3 and MFGE8 regulate vesicle-mediated eggshell calcication in a new model for avian biomineralization. J Biol Chem. 2019;294(40):14526-14545.

231. Sun T, Xiao C, Deng J, Yang Z, Xu W, Zou L, Du W, Li S, Huo X, Zeng L, et al. Transcriptome Analysis Reveals Key Genes and Pathways Associated with Egg Production in Nandan-Yao Domestic Chicken. 2020.

232. Yaba A, Demir N. The mechanism of mTOR (mammalian target of rapamycin) in a mouse model of polycystic ovary syndrome (PCOS). J Ovarian Res. 2012;5:38

233. Birkl P, Chow J, Forsythe P, Gostner JM, Kjaer JB, Kunze WA, McBride P, Fuchs D, Harlander-Matauschek A. The role of tryptophan-kynurenine in feather pecking in domestic chicken lines. Front. Vet. Sci. 2019;6:209.

234. Miura H, Ozaki N, Sawada M, Isobe K, Ohta T, Nagatsu T. A link between stress and depression: shifts in the balance between the kynurenine and serotonin pathways of tryptophan metabolism and the etiology and pathophysiology of depression. Stress. 2008;11:198-209.

235. Kim J, Choi YH. Differential abundance of egg white proteins in laying hens treated with corticosterone. J. Agric. Food Chem. 2014;62,12346-12359.

236. Mazerbourg S, Bondy CA, Zhou J, Monget, P. The insulin-like growth factor system: a key determinant role in the growth and selection of ovarian follicles? a comparative species study. Reprod. Domest. Anim. 2003;38:247-258.

237. Zhou J, Kumar TR, Matzuk MM, Bondy C. Insulin-like growth factor I regulates gonadotropin responsiveness in the murine ovary. Mol. Endocrinol. 1997;11:1924-1933.

238. Wang HB, Li H, Wang QG, Zhang XY, Wang SZ, Wang YX, Wang XP. Profiling of chicken adipose tissue gene expression by genome array. BMC Genomics. 2007;8(1):1-4

239. Nagaraja SC, Aggrey SE, Yao J, Zadworny D, Fairfull RW, Kuhnlein U. Trait association of a genetic marker near the IGF-I gene in egg-laying chickens. J. Hered. 2000;91:150-156.

240. Bain MM, McDade K, Burchmore R, Law A, Wilson PW, Schmutz M, Preisinger R, Dunn IC. Enhancing the egg's natural defence against bacterial penetration by increasing cuticle deposition. Anim Genet. 2013;44(6):661-668.

241. Rose-Martel M, Du J, Hincke MT. Proteomic analysis provides new insight into the chicken eggshell cuticle. J Proteome. 2012;75(9):2697-2706.

242. Mann K, Macek B, Olsen JV. Proteomic analysis of the acid-soluble organic matrix of the chicken calcified eggshell layer. Proteomics. 2006;6(13):38013810.

243. Bar A. Calcium transport in strongly calcifying laying birds: mechanisms and regulation. Comp Biochem Physiol a-Mol Integr Physiol. 2009;152(4):447469.

244. Pertiñez SP, Wilson PW, Icken W, Cavero D, Bain MM, Jones AC, Dunn IC. Transcriptome analysis of the uterus of hens laying eggs differing in cuticle deposition. BMC Genomics. 2020;21(1):1-5.

\section{Tables}

Table 1. Ranking of the candidate reference genes according to their stability value per indicated software 


\begin{tabular}{|c|c|c|c|c|c|c|c|c|c|c|}
\hline \multirow[t]{2}{*}{ Gene Name } & \multicolumn{2}{|c|}{ geNorm } & \multicolumn{2}{|c|}{ NormFinder } & \multicolumn{2}{|c|}{ BestKeeper } & \multicolumn{2}{|c|}{$\Delta \mathrm{CT}$} & \multicolumn{2}{|c|}{ Comprehensive } \\
\hline & $\mathrm{M}$ & $\mathbf{R}$ & SV & $\mathbf{R}$ & SD & $\mathrm{R}$ & SD & $\mathrm{R}$ & GM & $\mathrm{R}$ \\
\hline 18S rRNA & 2.05 & 18 & 3.019 & 19 & 1.83 & 6 & 3.75 & 20 & 14.43 & 18 \\
\hline ALB & 3.00 & 23 & 5.988 & 24 & 2.54 & 10 & 6.32 & 24 & 19.28 & 23 \\
\hline B2MG & 2.70 & 22 & 4.015 & 23 & 1.66 & 4 & 4.4 & 23 & 14.85 & 19 \\
\hline BActin & 1.48 & 13 & 2.38 & 16 & 4.12 & 23 & 2.88 & 16 & 16.94 & 21 \\
\hline DNAJC24 & 1.60 & 15 & 2.709 & 17 & 4.37 & 24 & 3.13 & 17 & 18.25 & 22 \\
\hline EEF1A1 & 1.54 & 14 & 0.871 & 4 & 1.73 & 5 & 2.43 & 9 & 7.21 & 6 \\
\hline GAPDH & 1.18 & 8 & 0.371 & 1 & 1.91 & 7 & 2.28 & 5 & 4.21 & 3 \\
\hline GUSB & 2.38 & 20 & 3.072 & 20 & 1.14 & 3 & 3.68 & 19 & 12.44 & 15 \\
\hline HMBS & 0.67 & 2 & 1.02 & 5 & 3.01 & 14 & 2.24 & 3 & 5.01 & 4 \\
\hline HSP10 & 1.01 & 6 & 1.863 & 14 & 3.79 & 21 & 2.54 & 12 & 12.54 & 16 \\
\hline HSP70 & 2.54 & 21 & 3.546 & 21 & 1.08 & 1 & 4.04 & 22 & 10.04 & 10 \\
\hline L-LDBC & 1.32 & 10 & 1.09 & 6 & 2.45 & 9 & 2.45 & 10 & 8.78 & 8 \\
\hline MRPS27 & 1.10 & 7 & 1.357 & 10 & 3.08 & 16 & 2.43 & 8 & 10.06 & 11 \\
\hline MRPS30 & 0.92 & 5 & 1.479 & 12 & 3.26 & 18 & 2.42 & 7 & 9.76 & 9 \\
\hline PGK2 & 0.38 & 1 & 0.523 & 3 & 2.59 & 11 & 2.13 & 2 & 2.85 & 2 \\
\hline PPP2CB & 2.23 & 19 & 2.912 & 18 & 1.11 & 2 & 3.55 & 18 & 10.67 & 13 \\
\hline RPL13 & 0.83 & 4 & 1.154 & 7 & 3.06 & 15 & 2.26 & 4 & 6.77 & 5 \\
\hline RPL14 & 1.66 & 16 & 1.445 & 11 & 2.15 & 8 & 2.66 & 13 & 11.81 & 14 \\
\hline RPL19 & 1.25 & 9 & 1.333 & 8 & 2.92 & 13 & 2.46 & 11 & 10.34 & 12 \\
\hline RPL23 & 1.43 & 12 & 2.087 & 15 & 3.64 & 20 & 2.77 & 15 & 15.55 & 20 \\
\hline RPL5 & 1.83 & 17 & 3.593 & 22 & 3.93 & 22 & 4.04 & 21 & 20.68 & 24 \\
\hline SDHA & 1.37 & 11 & 1.835 & 13 & 3.45 & 19 & 2.7 & 14 & 14.27 & 17 \\
\hline TBP & 0.78 & 3 & 1.352 & 9 & 3.23 & 17 & 2.35 & 6 & 7.78 & 7 \\
\hline TFRC & 0.38 & 1 & 0.4 & 2 & 2.59 & 12 & 2.1 & 1 & 2.21 & 1 \\
\hline
\end{tabular}

$M$, the gene expression stability measure; $S D$, standard deviation value; $S V$, stability value; $G M$, geomean value and $R$, ranking

Figures

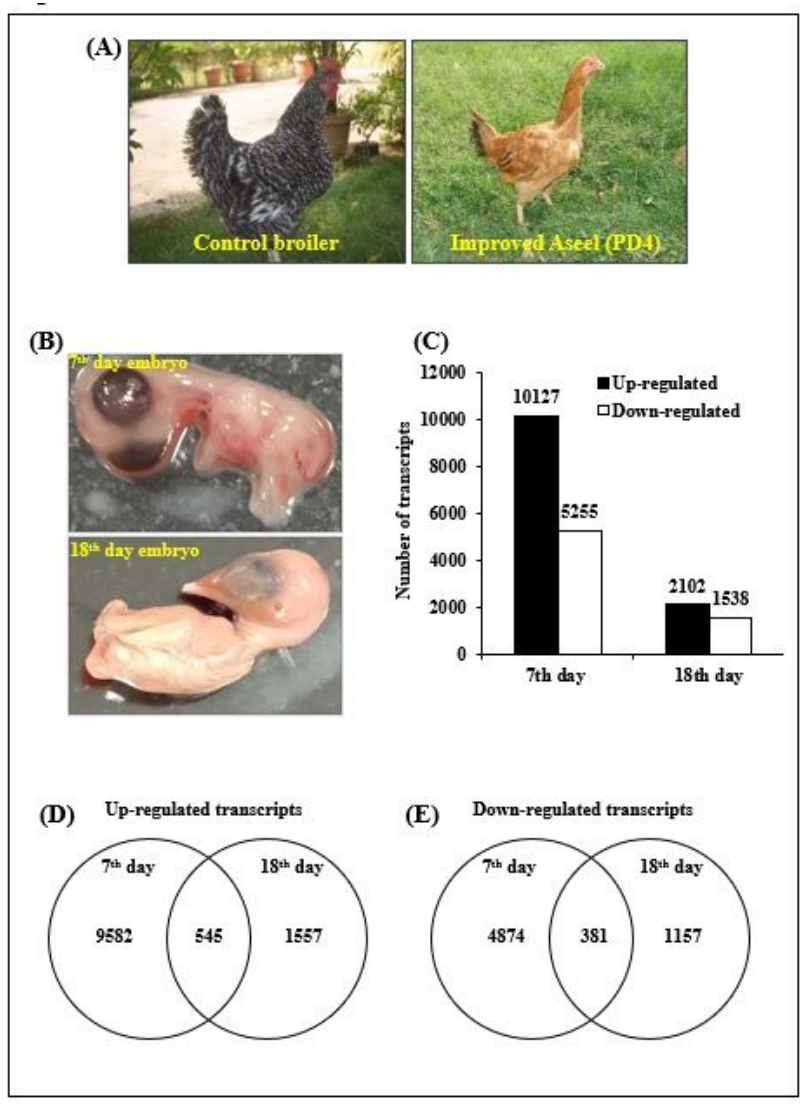


Table 2.Ranking of the candidate reference genes according to their stability value per indicated software

\begin{tabular}{|c|c|c|c|c|c|c|}
\hline $\begin{array}{c}\text { S. } \\
\text { No }\end{array}$ & Gene Name & Accession No. & Primer Sequence & $\operatorname{Tm}$ & GC\% & $\begin{array}{l}\text { Amplicon } \\
\text { Size (bp) }\end{array}$ \\
\hline \multirow[t]{2}{*}{1} & \multirow[t]{2}{*}{ Destrobrevin alpha (D alpha) } & \multirow[t]{2}{*}{ CR733292.1 } & 5'-CAACCCTTTGTGGAGGAAAGA-3' & 62 & 47.6 & \multirow[t]{2}{*}{114} \\
\hline & & & 5'-GAACCTCCCGCAGAAACAA-3' & 62 & 52.6 & \\
\hline \multirow[t]{2}{*}{2} & \multirow[t]{2}{*}{ Uncharacterized protein (UP5) } & \multirow[t]{2}{*}{ ES605836.1 } & 5'-GAACCAAATGCTGGCAGAAG-3' & 62 & 50 & \multirow[t]{2}{*}{112} \\
\hline & & & 5'-AAATACTCTCTGGGTGAACAGG-3' & 62 & 45.5 & \\
\hline \multirow[t]{2}{*}{3} & \multirow[t]{2}{*}{ Toll interacting protein (TOLLIP) } & \multirow[t]{2}{*}{ NM_001006471.1 } & 5'-GTGTAACGAAGAGGACCTGAAA-3' & 62 & 45.5 & 95 \\
\hline & & & 5'-TGTTCCCTCTCTGAGCTTCTA-3' & 62 & 47.6 & \\
\hline 4 & Asw & CN225783.1 & 5'-GGCAACACGTGAAATCCATTC-3' & 62 & 47.6 & 119 \\
\hline & & & 5'-GCGCACGTCTCTGTATTCT-3' & 62 & 52.6 & \\
\hline 5 & Chain A, Fibrinogen alpha subunit (Chain A FAS) & BX935039.1 & 5'-TGACGACACAGACCAGAATTAC-3' & 62 & 45.5 & 106 \\
\hline & & & 5'-GGTTTCCACAATTACCCGATTG-3' & 62 & 45.5 & \\
\hline 6 & Hypothetical protein (HP29) & AW198329.1 & 5'-CCCAGATGACAGAAGAACAAATAAAG-3' & 62 & 38.5 & 106 \\
\hline & & & 5'-CCСTCTTCTCCAAAGCATGTAT-3' & 62 & 45.5 & \\
\hline 7 & Fibrinogen gamma chain precursor (FGCP) & BG642009.1 & 5'-CTGGTCACCTCAATGGACAATA-3' & 62 & 45.5 & 106 \\
\hline & & & 5'-CATCGGTCACGCCATGTT-3' & 62 & 55.6 & \\
\hline 8 & Apolipoprotein B precursor (ALPBP) & NM_001044633.1 & 5'-CTTGAGGCCAACTCCAAAGTA-3' & 62 & 47.6 & 102 \\
\hline & & & 5'-GTGCTCCCAGACTGCATAAA-3' & 62 & 50 & \\
\hline 9 & Maestro heat-like repeat-containing protein family member 2B & CR406681.1 & 5'-CTGGAACACACCACAGACTT-3' & 62 & 50 & 130 \\
\hline & (MHCRCP2B) & & 5'-CCCGATAGATGTCCTTTCCATAC-3' & 62 & 47.8 & \\
\hline 10 & Activin A receptor, type IB (AARIB) & XM_001231300 & 5’-GCACGGATCTCTCTTTGACTAC-3' & 62 & 50 & 120 \\
\hline & & & 5'-TGAGTACCCACGATCTCCAT-3' & 62 & 50 & \\
\hline 11 & cAMP responsive element modulator (CREM) & NM_204387 & 5'-CAAGAGAGAGCTGCGACTTATG-3' & 62 & 50 & 102 \\
\hline & & & 5'-AGCACAGCCACACGATTT-3' & 62 & 50 & \\
\hline 12 & Caveolin 1, caveolae protein, 22kDa (CAV1) & NM_001105664 & 5'-CATTCCCATGGCACTCATCT-3' & 62 & 50 & 106 \\
\hline & & & 5'-GCACTGGATCTCAATCAGGTAG-3' & 62 & 50 & \\
\hline 13 & Caveolin 2 (CAV2) & NM_001007086 & 5’-TGCTGTACAAGCTGCTGAG-3' & 62 & 52.6 & 140 \\
\hline & & & 5'-CACTGAAGGCAAGACCATGA-3' & 62 & 50 & \\
\hline 14 & Follistatin-like 1 (FSTL1) & NM_204638 & 5'-CGATGACATGTGAAGGGAAGA-3' & 62 & 47.6 & 105 \\
\hline & & & 5'-TCTGCAGCTCCTGAACATATC-3' & 62 & 47.6 & \\
\hline 15 & WAP, follistatin/kazal, immunoglobulin, kunitz and netrin domain & NP9672441 & 5'-GAGGGCAACAACAACAACTTC & 62 & 47.6 & 109 \\
\hline & containing 1 (WAPFK) & & 5'-TCAGCACCATCTTGCTCTTC-3' & 62 & 50 & \\
\hline 16 & Glucose-6-phosphate isomerase (GPI) & NM_001006128 & 5’-CACTTCTGCCCTATGACCAATA-3' & 62 & 45.5 & 110 \\
\hline & & & 5'-GTAGTCCACACGAGATCCTTTC-3' & 62 & 50 & \\
\hline 17 & Solute carrier family 2 (facilitated glucose transporter), member 3 & NM_205511 & 5'-GTGGTACACAGGATGTATCTCAAG-3' & 62 & 45.8 & 112 \\
\hline & (SLC2A3) & & 5'-CGATAGTTTGGAGAGCGGAATAG-3' & 62 & 47.8 & \\
\hline 18 & Heat shock 60kDa protein 1 (chaperonin) (HSPD1), nuclear gene & NM_001012916 & 5'-GGTGAGAAGGCTCAGATTGAA-3' & 62 & 47.6 & 122 \\
\hline & encoding mitochondrial protein & & 5'-GCTACTCCGTCAGATAGTTTGG-3' & 62 & 50 & \\
\hline 19 & Heat shock 70kDa protein 5 (glucose-regulated protein, 78kDa) & NM_205491 & 5'-TGAGACAGTTGGAGGTGTAATG-3' & 62 & 45.5 & 103 \\
\hline & (HSPA5) & & 5'-AGTGGGCTGATTGTCAGAAG-3' & 62 & 50 & \\
\hline 20 & Heat shock 70kDa protein 8 (HSPA8) & NM_205003 & 5'-AGTTTGAGCTGACCGGTATTC-3' & 62 & 47.6 & 122 \\
\hline & & & 5'-CTCCTTGCCAGTGCTCTTATC-3' & 62 & 52.4 & \\
\hline 21 & Heat shock factor binding protein 1 (HSBP1) & NM_001112809 & 5'-ATGCAGGACAAATTTCAAACCA-3' & 62 & 36.4 & 118 \\
\hline & & & 5’-CTACTCCCGCTTGTGTCATC-3' & 62 & 55 & \\
\hline 22 & Heat shock transcription factor 1 (HSTF 1) & BM440477 & 5'-GCAGCAGAAGGTGGTCAATA-3' & 62 & 50 & 146 \\
\hline & & & 5'-AGTACTGGCGGCTGTATTTC-3' & 62 & 50 & \\
\hline 23 & Partial mRNA for heat shock protein 70 (hsp70 gene) & AJ301880 & 5'-CCCAGTAAGTGCGGGTCATAA-3' & 64 & 52.4 & 85 \\
\hline & & & 5'-CGCTCCGCCAGTCACTT-3' & 64 & 64.7 & \\
\hline 24 & Homeobox C9 (HBC9) & BX950823 & 5'-AGATGTCCGTACACAAAGTATCA-3' & 62 & 39.1 & 105 \\
\hline & & & 5'-GTTTAGGACTCGGGCTACTTC-3' & 62 & 52.4 & \\
\hline 25 & Insulin-like growth factor 1 receptor (IGF1R) & NM_205032 & 5'-TGTGTACGTTCCAGACGAATG-3' & 62 & 47.6 & 104 \\
\hline & & & 5'-CCTTGGCTATTCCCTCATACAC-3' & 62 & 50 & \\
\hline 26 & Insulin-like growth factor binding protein 1 (IGFBP1) & NM_001001294 & 5’-CAGGACCAGATGCTGAACTATC-3' & 62 & 50 & 134 \\
\hline & & & 5'-CCCTGTTCTTTCCATTTCTTGTG-3' & 62 & 43.5 & \\
\hline 27 & Mitogen-activated protein kinase 8 interacting protein 3 (MAPK8IP3) & XM_424591 & 5'-GTGATGACAACAGCGACAAATC-3' & 62 & 45.5 & 118 \\
\hline & & & 5'-CCAGGCACAGAGACAAAGAA-3' & 62 & 50 & \\
\hline 28 & Mitogen-activated protein kinase kinase kinase 4 (MAPKKK4) & CR523470 & 5'AGTGGATGAACTACGTGCTAAC-3' & 62 & 45.5 & 120 \\
\hline & & & 5'-CCGGGAGAGCCGAAATAAAT-3' & 62 & 50 & \\
\hline 29 & Mitogen-activated protein kinase-activated protein kinase 3 & XM_414262 & 5’-CTGAAGACTGACCCAACAGAG-3' & 62 & 52.4 & 139 \\
\hline & (MAPKAPK3) & & 5'-CTTCATCCCAGTGGTCCTTATC-3' & 62 & 50 & \\
\hline 30 & Myozenin 2 (MZ2) & BX930590 & 5'-GAAACAACAAGCATCAGCCATTA-3' & 62 & 39.1 & 121 \\
\hline & & & 5’-GCTGAGTGTTGATAGTTCCTCTAC-3' & 62 & 45.8 & \\
\hline 31 & Angiotensin II receptor, type 1 (AGTR1) & NM_205157 & 5'-TTCCTGGATTCCTCATCAAGTG-3' & 62 & 45.5 & 103 \\
\hline & & & 5'-GGGCATAGCTGTATCCACAATA-3' & 62 & 45.5 & \\
\hline 32 & Angiotensin II receptor-associated protein (AGTRAP) & BX930324 & 5'-CTTCAACATAGGTCTCAACCGT-3' & 62 & 45.5 & 106 \\
\hline & & & 5'-CTGAGCTGCCTTGCTTGA-3' & 62 & 55.6 & \\
\hline 33 & CD9 molecule (CD9) & NM_204762 & 5'-TACTACAATGCCATGCCCTAAA-3' & 62 & 40.9 & 134 \\
\hline & & & 5'-TAGCACAGCAAAGAACCATACT-3' & 62 & 40.9 & \\
\hline 34 & Dickkopf homolog 2 (DKK2) & XM_420494 & 5'-CGCAACAAGAAGAACAGTCATTAT-3' & 62 & 37.5 & 105 \\
\hline & & & 5'-GGGATCACCTTCATGTCCTTTA-3' & 62 & 45.5 & \\
\hline 35 & Glycoprotein M6A (GPM6A) & NM_001012579 & 5'-GGATCTTCGCCAGTATGGTATT-3' & 62 & 45.5 & 97 \\
\hline
\end{tabular}

Page 21/27 


\begin{tabular}{|c|c|c|c|c|c|c|}
\hline & & & 5'-TAGCTCATTCGAGTCACACATC-3' & 62 & 45.5 & \\
\hline \multirow[t]{2}{*}{36} & \multirow[t]{2}{*}{ Glycoprotein M6B (GPM6B) } & \multirow[t]{2}{*}{ NM_001012545 } & 5'-GAACATCTGCAACACGAATGAG-3' & 62 & 45.5 & \multirow[t]{2}{*}{124} \\
\hline & & & 5'-GGCCCAGTTAGAAGACAGTATC-3' & 62 & 50 & \\
\hline \multirow[t]{2}{*}{37} & \multirow[t]{2}{*}{ Janus kinase 1 (JAK1) } & \multirow[t]{2}{*}{ NM_204870 } & 5'-CAAGGAACTAGCTGACCTGATG-3' & 62 & 50 & \multirow[t]{2}{*}{98} \\
\hline & & & 5'-CCTCCAGTTTGTTGATGTCTCT-3' & 62 & 45.5 & \\
\hline \multirow[t]{2}{*}{38} & \multirow[t]{2}{*}{ Janus kinase 2 (JAK2) } & NM_001030538 & 5'-GATGGATGCCCTGATGAGATT-3' & 62 & 47.6 & 92 \\
\hline & & & 5'-CGCTGAGCAAGATCCCTAAA-3' & 62 & 50 & \\
\hline 39 & Janus kinase and microtubule interacting protein 2 (JAKMIP2) & CR390426 & 5'-GACTGCATCAGTTCATCATTTCTC-3' & 62 & 41.7 & 130 \\
\hline & & & 5'-ACAGGAACACATTGCTGGT-3' & 62 & 47.4 & \\
\hline 40 & Janus kinase and microtubule interacting protein 3 (JAKMIP3) & XM_426548 & 5'-TATCAACTTCCACCACGTTCC-3' & 62 & 47.6 & 100 \\
\hline & & & 5'-CATCAGCTCTGCCACTACTATG-3' & 62 & 50 & \\
\hline 41 & Leiomodin 3 (fetal) (LMOD3) & BX935813 & 5'-GAGAATGACTGCAGAGGAGATG-3' & 62 & 50 & 97 \\
\hline & & & 5’-TTTGTAGTGCCGCTCCTTC-3' & 62 & 52.6 & \\
\hline 42 & Musculoskeletal, embryonic nuclear protein 1 (MUSTN1) & NM_213580 & 5'-CCAAGTCATGAAGCAGTGTGA-3' & 63 & 47.6 & 94 \\
\hline & & & 5'-TGACTTCTCAAAGACCGTTTCG-3' & 63 & 45.5 & \\
\hline 43 & Myosin binding protein C, fast type (MYBPC2) & NM_001044659 & 5'-CTGATGGAGCGCAAGAAGAA-3' & 62 & 50 & 105 \\
\hline & & & 5'-GAAGACGCCCTCGATCATTT-3' & 62 & 50 & \\
\hline 44 & Myosin binding protein C, slow type (MYBPC1) & BX935207 & 5'-CCTGAAACGTAGGGAGGTTAAA-3' & 62 & 45.5 & 131 \\
\hline & & & 5'-TGCCTCTCAGGTCAGTGATA-3' & 62 & 50 & \\
\hline 45 & Perilipin 1 (PLIN1) & NM_001127439 & 5'-CCAGAAGAGGAGGAGGAAGAT-3' & 62 & 52.4 & 100 \\
\hline & & & 5'-TAGCACTGTGAGCCCTGTA-3' & 62 & 52.6 & \\
\hline 46 & Phospholamban (PLN) & NM_205410 & 5'-CGATAGCAGGGTTTCCATACTT-3' & 62 & 45.5 & 117 \\
\hline & & & 5'-TGTCAGCTCTCTCCAGTAGAA-3' & 62 & 47.6 & \\
\hline 47 & RCD1 required for cell differentiation1 homolog (S. pombe) & NM_001006521 & 5'-TGATTGGAGCCTTGGTGAAA-3' & 62 & 45 & 105 \\
\hline & $(\mathrm{RQCD} 1)$ & & 5'-GTTCACTGCCAGACTCCATAAT-3' & 62 & 45.5 & \\
\hline 48 & Slow muscle troponin T (TNNT1) & NM_205114 & 5'-CCCTCCACATTGAGCACAT-3' & 62 & 52.6 & 104 \\
\hline & & & 5'-CTCCATCAGGTCGAACTTCTC-3' & 62 & 52.4 & \\
\hline 49 & Troponin T type 3 (skeletal, fast) (TNNT3) & NM_204922 & 5'-GAAGCAAACAGCTAGAGAGACA-3' & 62 & 45.5 & 125 \\
\hline & & & 5'-GGTATAACCAGTCCCACAGTTC-3' & 62 & 50 & \\
\hline 50 & Troponin I type 1 (skeletal, slow) (TNNI1) & BX931462 & 5'-TCTCTTCGTCCACAATCTCAAC-3' & 62 & 45.5 & 128 \\
\hline & & & 5'-ACAGTCGGAGAAGGAGAGATAC-3' & 62 & 50 & \\
\hline 51 & Myostatin (MSTN) & NM_001001461.1 & 5'-GGATGGGACTGGATTATAGCAC-3' & 62 & 50 & 97 \\
\hline & & & 5'-GGTGAGTGTGCGGGTATTT-3' & 62 & 52.6 & \\
\hline 52 & Follistatin (FST) & NM_205200.1 & 5'-ACAACTTATCCGAGCGAGTG-3' & 62 & 50 & 112 \\
\hline & & & 5'-CTTCCTCTGGGTCTTCGTTAAT-3' & 62 & 45.5 & \\
\hline 53 & Activin A receptor type 2A (ACVR2A) & NM_205367.1 & 5’-GCAAGAATGTGCTGCTGAAA-3' & 62 & 45 & 109 \\
\hline & & & 5'-CCAACCTGTCCATGTGTATCT-3' & 62 & 47.6 & \\
\hline 54 & Activin A receptor type 2B (ACVR2B) & NM_204317.1 & 5'-GAAGTGTTAGAGGGAGCAATCA-3' & 62 & 47.5 & 118 \\
\hline & & & 5'-CTGGACCATCAACTGCTCTAC-3' & 62 & 52.4 & \\
\hline 55 & SMAD family member 2-Z (SMAD2Z) & NM_204561.1 & 5'-GGGAGTGCGTCTCTATTACATC-3' & 62 & 50 & 110 \\
\hline & & & 5'-CAGGATGCCAGCCATATCTT-3' & 62 & 50 & \\
\hline 56 & SMAD family member 3 (SMAD3) & NM_204475.1 & 5'-GGCTATTTGAGTGAGGATGGAG-3' & 62 & 50 & 123 \\
\hline & & & 5'-GGGCTGCAGATCCAGATTATT-3' & 62 & 47.6 & \\
\hline 57 & Activin A receptor type 1B (ACVR1B) & XM_015300267.2 & 5'-GCACGGATCTCTCTTTGACTAC-3' & 62 & 50 & 120 \\
\hline & & & 5'-TGAGTACCCACGATCTCCAT-3' & 62 & 50 & \\
\hline 58 & Transforming growth factor beta receptor 1 (TGFBR1) & NM_204246.1 & 5'-TCGTGTGCCAAGTGAAGAAG-3' & 62 & 50 & 102 \\
\hline & & & 5'-CCAGAGCCTGAAGTTGTCATATC-3' & 63 & 47.8 & \\
\hline 59 & Myogenin (MYOG) & NM_204184.1 & 5'-GGCTGAAGAAGGTGAACGAA-3' & 62 & 50 & 116 \\
\hline & & & 5'-GCGCTCGATGTACTGGATG-3' & 62 & 57.9 & \\
\hline 60 & Mitogen-activated protein kinase kinase 6 (MAP2K6) & XM_003642348.2 & 5'-CTCAGCAGAGTTCGTCGATTT-3' & 62 & 47.6 & 101 \\
\hline & & & 5'-GCAGGGTGAAGAAAGGATGT-3' & 62 & 50 & \\
\hline 61 & Mitogen-activated protein kinase kinase kinase 7 (MAP3K7) & XM_015284683.2 & 5'-CAGCCCTTGTTTCAGGAGAAG-3' & 63 & 52.4 & 101 \\
\hline & & & 5'-GCCTCGTTTAGGCTTGGAATAG-3' & 63 & 50 & \\
\hline 62 & Caveolin 3 (CAV3) & NM_204370.2 & 5'-GCTTTGATGGTGTCTGGAAAG-3' & 61 & 47.6 & 142 \\
\hline & & & 5’-ATGTGGCAGAAGGAGATGAG-3' & 61 & 50 & \\
\hline 63 & Heat shock protein 70 (HSP70) & J02579.1 & 5'-GGATGAAGCCAACAGAGATAGG-3' & 62 & 50 & 117 \\
\hline & & & 5'-TTGTCCTGGTCACTGATCTTTC-3' & 62 & 45.5 & \\
\hline 64 & Protein kinase AMP-activated catalytic subunit alpha 1 (PRKAA1) & NM_001039603.1 & 5'-CTTGACGATCACCATCTGTCTC-3' & 62 & 50 & 140 \\
\hline & & & 5'-TGCCACTTCGCTCTTCTTAC-3' & 62 & 50 & \\
\hline 65 & Protein kinase AMP-activated catalytic subunit alpha 2 (PRKAA2) & NM_001039605.1 & 5'-GGAGGTCTGTGAGAAGTTTGAG-3' & 62 & 50 & 124 \\
\hline & & & 5'-GTTCATGATCCTCCGGTTGT-3' & 62 & 50 & \\
\hline 66 & Creatine kinase, M-type (CKM) & NM_205507.1 & 5'-CGACCACTTCCTGTTCGATAA-3' & 62 & 47.6 & 109 \\
\hline & & & 5'-GAACGTCTTGTTGTCGTTGTG-3' & 62 & 47.6 & \\
\hline 67 & Mechanistic target of rapamycin (serine/threonine kinase) (MTOR) & XM_417614.5 & 5'-AAGGTTTCTTCCGGTCCATATC-3' & 62 & 45.5 & 98 \\
\hline & & & 5’-ATCAGGCCAGTGACCATAATC-3' & 62 & 47.6 & \\
\hline 68 & Ribosomal protein S6 kinase A1 (RPS6KA1) & NM_001109771.2 & 5'-GGAACCCAGCCAACAGATTA-3' & 62 & 50 & 104 \\
\hline & & & 5'-TTCCCTTCGGTACAGCTTATTC-3' & 62 & 45.5 & \\
\hline 69 & Carnitine palmitoyltransferase I (CPT1) & DQ314726.1 & 5'-GCCTTCGTGCGCAGTAT-3' & 62 & 58.8 & 146 \\
\hline & & & 5’-ACGTAGAGGCAGAAGAGGT-3’' & 62 & 52.6 & \\
\hline 70 & Acyl-CoA synthetase long-chain family member 1 (ACSL1) & NM_001012578.1 & 5'-GCCAGTACGTAGGCATCTTT-3' & 62 & 50 & 116 \\
\hline & & & 5'-TGCTTCAGTTCCCAGTGTATC-3' & 62 & 47.6 & \\
\hline 71 & Enoyl-CoA hydratase, short chain 1 (ECHS1) & NM_001277395.1 & 5'-CAGGTGGGAGCTATTGTCATC-3' & 62 & 52.4 & 97 \\
\hline
\end{tabular}

Page 22/27 


\begin{tabular}{|c|c|c|c|c|c|c|}
\hline & & & 5'-CATAGCACTCCTGGAAGGTTT-3' & 62 & 47.6 & \\
\hline \multirow{2}{*}{72} & \multirow{2}{*}{ Hydroxyacyl-CoA dehydrogenase (HADH) } & \multirow[t]{2}{*}{ NM_001277897.1 } & 5'-GCTATCCCATGGGTCCATTT-3' & 62 & 50 & \multirow[t]{2}{*}{100} \\
\hline & & & 5'-AGAGGATTGTTGGGCTCTATTG-3' & 62 & 45.5 & \\
\hline \multirow[t]{2}{*}{73} & \multirow[t]{2}{*}{ Acyl-CoA oxidase 2 (ACOX2) } & \multirow[t]{2}{*}{ XM_015293306.2 } & 5'-TGCCACCATCTGTCACTTATC-3' & 62 & 47.6 & \multirow[t]{2}{*}{141} \\
\hline & & & 5'-TAGCTGCTGTGCTGCTTATC-3' & 62 & 50 & \\
\hline \multirow[t]{2}{*}{74} & \multirow[t]{2}{*}{ Sterol regulatory element binding protein 1 (SREBP1) } & \multirow[t]{2}{*}{ AJ310768.1 } & 5'-CATGGAGGTGGCGAAGG-3' & 62 & 64.7 & \multirow[t]{2}{*}{134} \\
\hline & & & 5'-TGTCAGGCTCGGAGTCA-3' & 62 & 58.8 & \\
\hline \multirow[t]{2}{*}{75} & \multirow[t]{2}{*}{ Fibroblast growth factor 2 (FGF2) } & \multirow[t]{2}{*}{ NM_205433.1 } & 5'-TTCGAGCGCTTGGAATCTAATA-3' & 62 & 40.9 & \multirow[t]{2}{*}{94} \\
\hline & & & 5'-GCTTGTACTGTCCAGTCCTTT-3' & 62 & 47.6 & \\
\hline \multirow[t]{2}{*}{76} & \multirow[t]{2}{*}{ Fibroblast growth factor receptor 1 (FGFR1) } & \multirow[t]{2}{*}{ NM_205510.1 } & 5'-CGTCACCAAAGTGGCTGTA-3' & 62 & 52.6 & \multirow[t]{2}{*}{98} \\
\hline & & & 5'-TGCCGATCATCTTCATCATCTC-3' & 62 & 45.5 & \\
\hline \multirow[t]{2}{*}{77} & \multirow[t]{2}{*}{ DNA methyltransferase 3 alpha (DNMT3A) } & \multirow[t]{2}{*}{ NM_001024832.1 } & 5'-CCTTCTTCTGGCTCTTTGAGAA-3' & 62 & 45.5 & \multirow[t]{2}{*}{111} \\
\hline & & & 5'-CAGACACCTCTTTGGCATCA-3' & 62 & 50 & \\
\hline \multirow[t]{2}{*}{78} & \multirow[t]{2}{*}{ Forkhead box O3 (FOXO3) } & \multirow[t]{2}{*}{ MK861853.1 } & 5'-CTCTCAGGCTCCTCTTTGTATTC-3' & 62 & 47.8 & \multirow[t]{2}{*}{109} \\
\hline & & & 5'-CACACTCCAAGCTCCCATT-3' & 62 & 52.6 & \\
\hline \multirow[t]{2}{*}{79} & \multirow[t]{2}{*}{ Peroxisome proliferator-activated receptor gamma (PPAR $\gamma$ ) } & \multirow[t]{2}{*}{ AF163811.1 } & 5'-CCCAAGTTTGAGTTTGCTGTG-3' & 62 & 47.6 & \multirow[t]{2}{*}{99} \\
\hline & & & 5'-TGGGCGATCTCCACTTAGTA-3' & 62 & 50 & \\
\hline \multirow[t]{2}{*}{80} & Myogenic factor 6 (MYF6) & FJ882409.1 & 5'-GCTGGATCAGCAGGACAAA-3' & 62 & 52.6 & 100 \\
\hline & & & 5'-GCAGGTGCTCAGGAAGTC-3' & 62 & 61.1 & \\
\hline 81 & Acetyl-CoA Carboxylase Alpha (ACACA) & NM_205505.1 & 5'-CAGATTTGTTGTCATGGTGAC-3' & 60 & 42.9 & 162 \\
\hline & & & 5'-ACAGCCTGCACTGGAATGC-3' & 60 & 57.9 & \\
\hline 82 & Acetyl-CoA Carboxylase Beta (ACACB) & XM_025155692.1 & 5'-GCTCCTGCTGCCCATATATTA-3' & 60 & 47.6 & 94 \\
\hline & & & 5'-GTCCGTGATGACACCTTTCT-3' & 60 & 50 & \\
\hline 83 & Fatty Acid Synthase (FASN) & NM_205155.3 & 5'-GTTCTCTGTACAGAGAATGTG-3' & 60 & 42.9 & 168 \\
\hline & & & 5'-CCATGTTTGACTTGGTTGATC-3' & 60 & 42.9 & \\
\hline
\end{tabular}

\section{Figure 1}

Differentially expressed transcripts in improved Aseel (PD4) during embryo development stages (7th and 18th-day embryos). (A) Fast (control broiler) and slow growth (Improved Aseel, PD4) birds are used in this study (B) Embryo tissues used for the transcriptome analysis. Complete embryo were used for 7thday and thigh muscle were used for 18th day. (C) Number of differentially expressed transcripts ( $P$ value $\leq 0.01$ and fold change $\geq 1$ ) in Aseel as compared to control broiler samples. (D) and (E) Number of commonly differentially expressed transcripts among the initial (7th-day) and developed (18th-day) embryo stages.

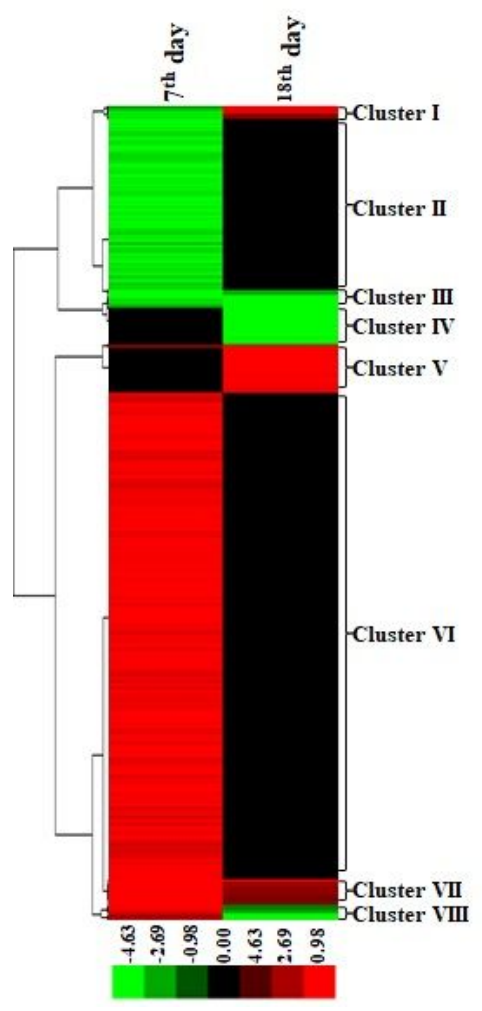

\section{Figure 2}

Hierarchical clustering of differentially expressed genes in 7th and 18th day of embryo (Aseel vs. control broiler). Hierarchical clustering of differentially expressed genes led to the formation of eight distinct clusters: I, II, III, IV, V, VI, VII and VIII, which include genes up and down regulated in muscle imitation and elongation stages of Aseel compared with control broiler, defines the specific molecular regulation of muscle growth. Each row represents the expression pattern of a single gene, and each column corresponds to a single sample: column 1,7 th day of embryo and column 2,18 th day of embryo. The expression 
levels are represented by color chat, with red representing the up regulation, green representing the down regulation and black representing the missing values or no change.

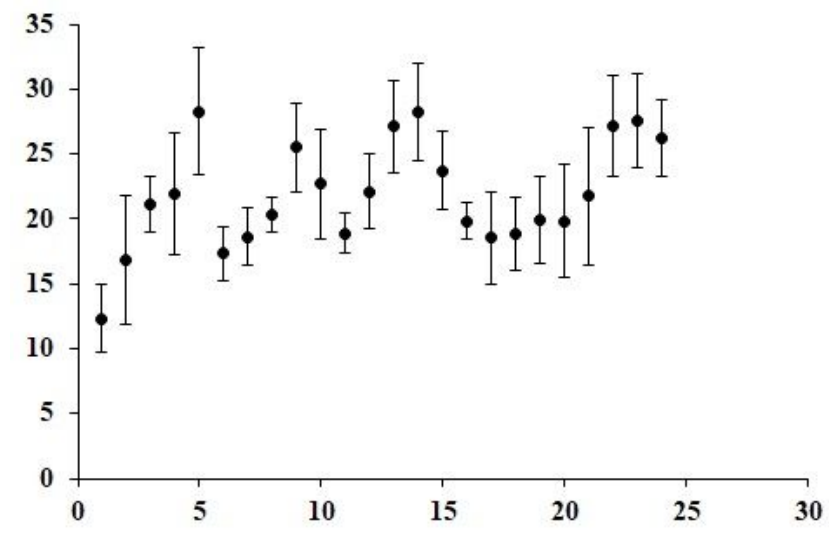

Figure 3

Identification of stable reference genes and variability of Ct values in the 7th-day embryo and 18th-day thigh muscle of improved Aseel and control broiler. Total RNA was isolated from embryo and thigh muscle tissues and converted to cDNA, and gene-specific primers were used in qPCR to determine Ct values. Mean \pm SD of Ct values are shown.

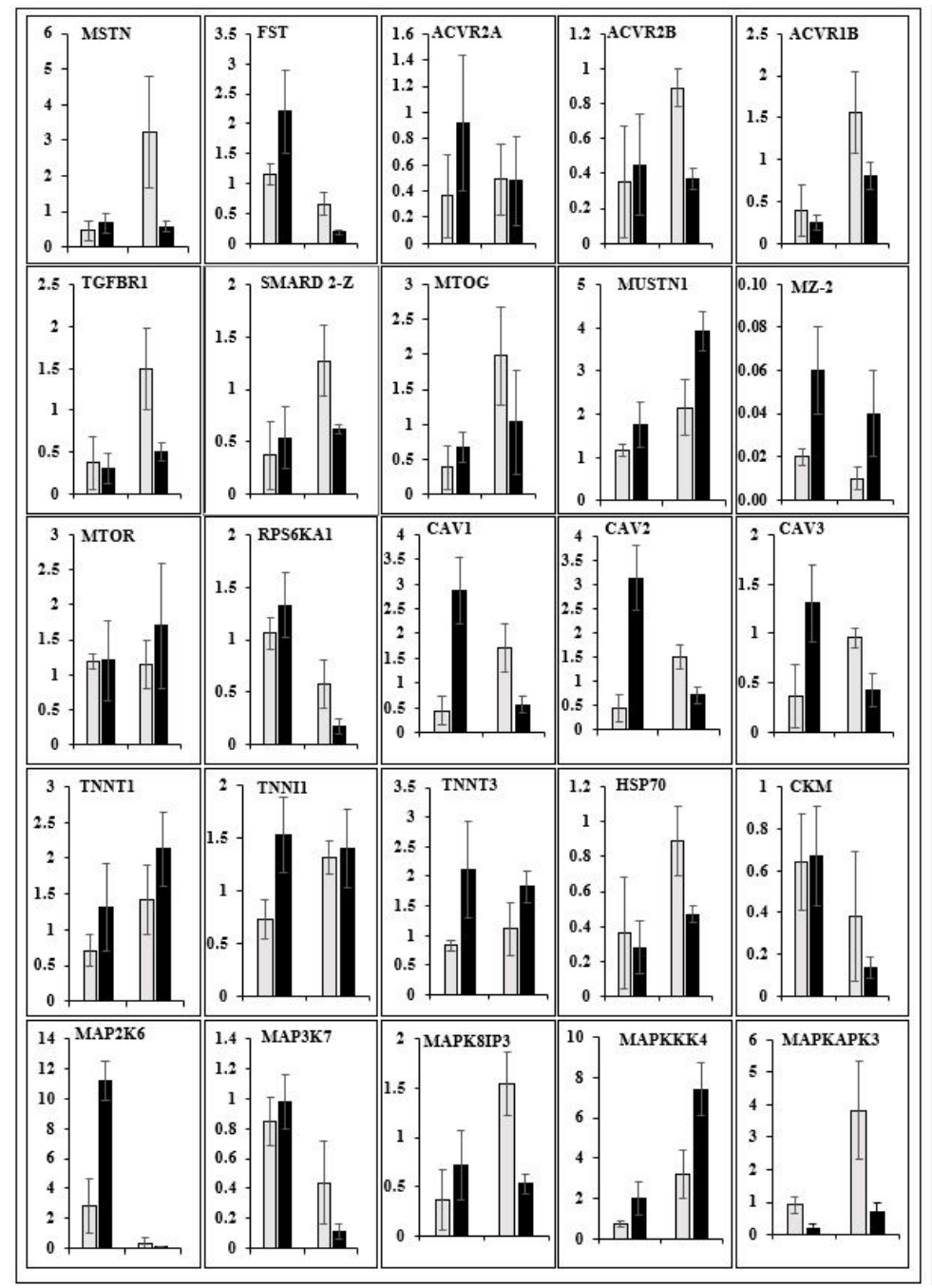

\section{Figure 4}

Relative expression of DEGs that are involved in muscle development, myostatin signaling, muscle metabolism (energy sensing and storage), and protein synthesis. Y-axis represents relative mRNA expression level and X-axis represents tissue samples used for qPCR study (Control broiler, PD4) 


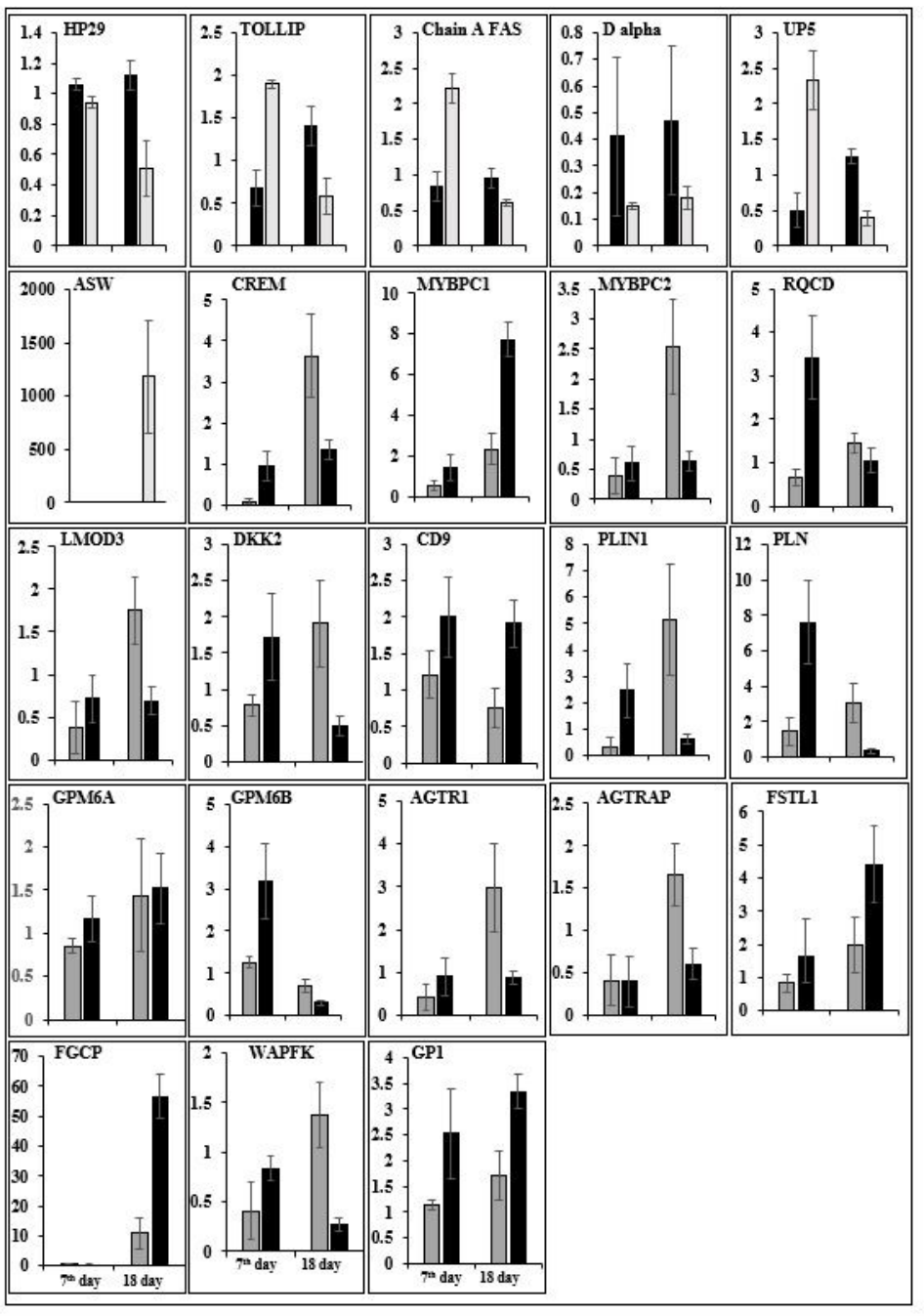

Figure 5

Relative expression of DEGs that are involved in embryo development. Y-axis represents relative mRNA expression level and X-axis represents tissue samples used for qPCR study ( Control broiler, PD4)

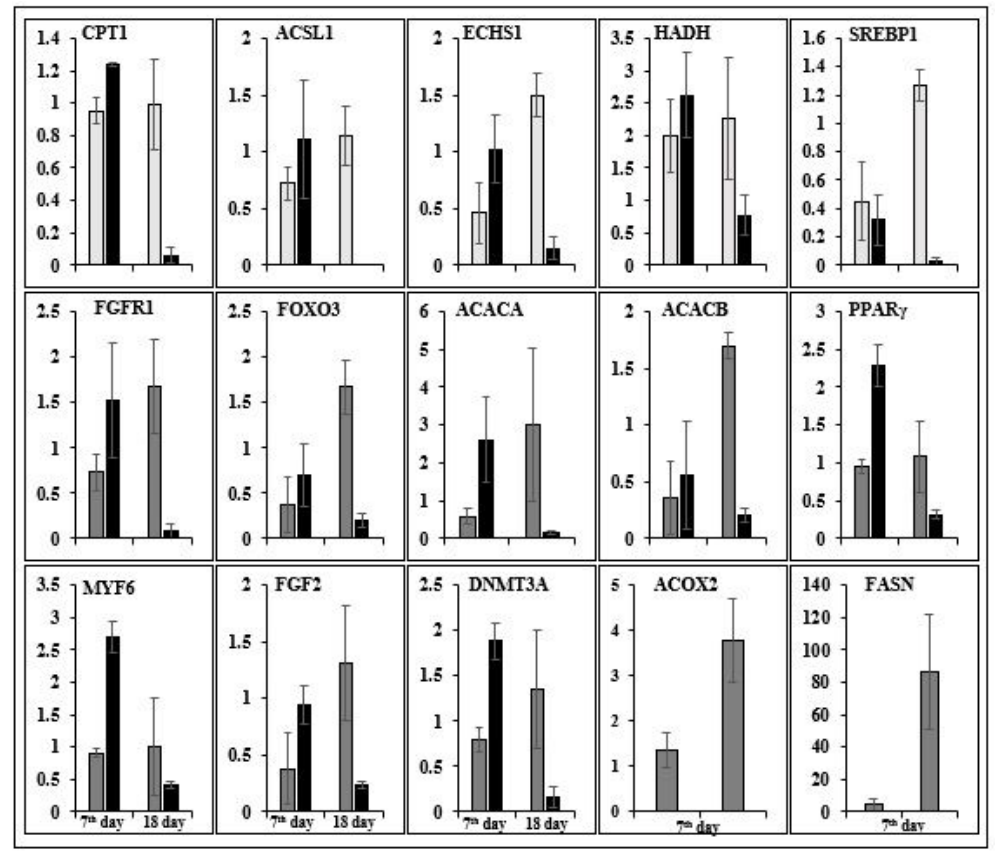

Figure 6 
Relative expression of DEGs that are involved in embryo development. Y-axis represents relative mRNA expression level and X-axis represents tissue samples used for qPCR study ( Control broiler, PD4)

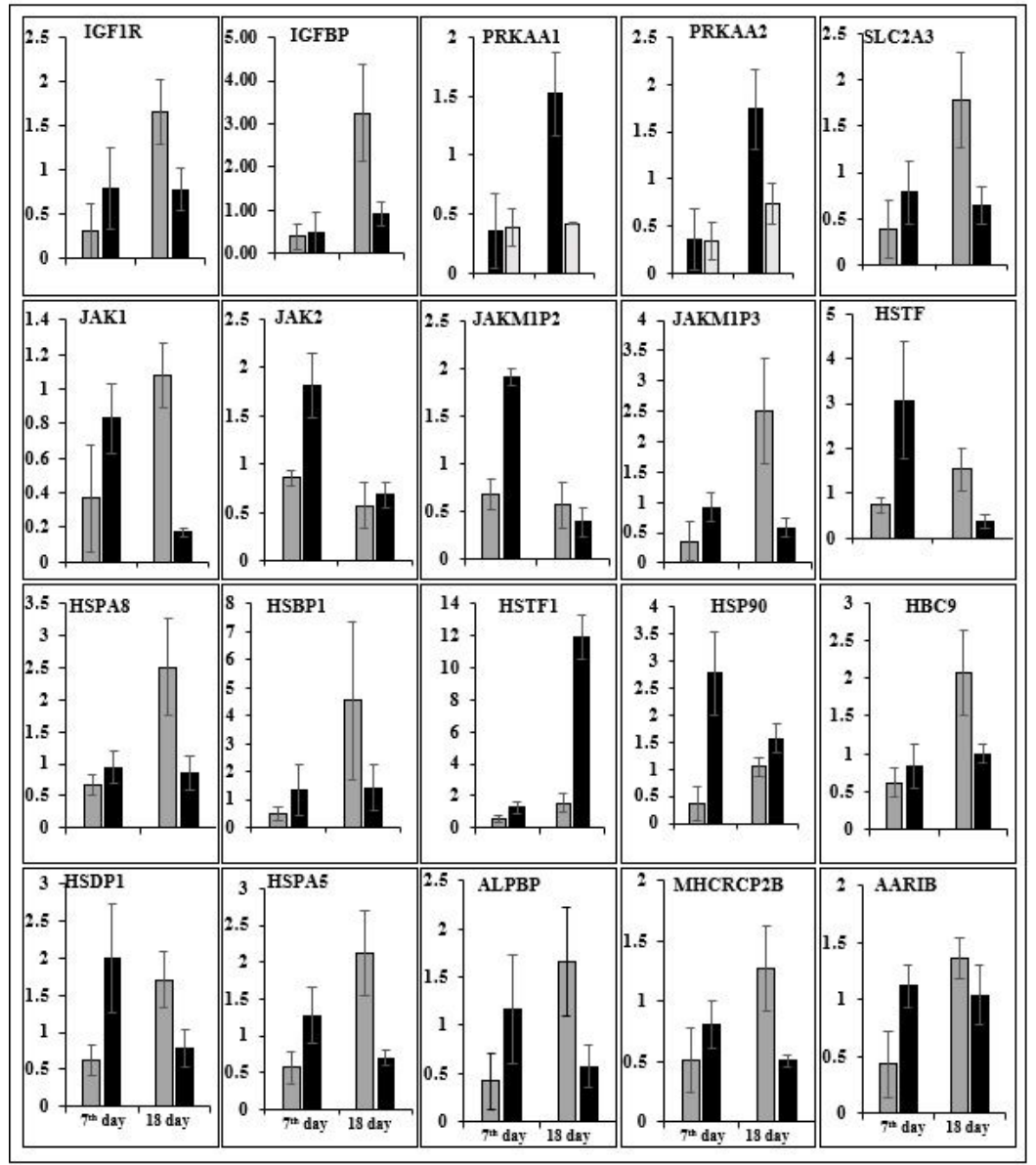

Figure 7

Relative expression of DEGs that are involved in cell signaling. Y-axis represents relative mRNA expression level and X-axis represents tissue samples used for qPCR study ( Control broiler, PD4) 


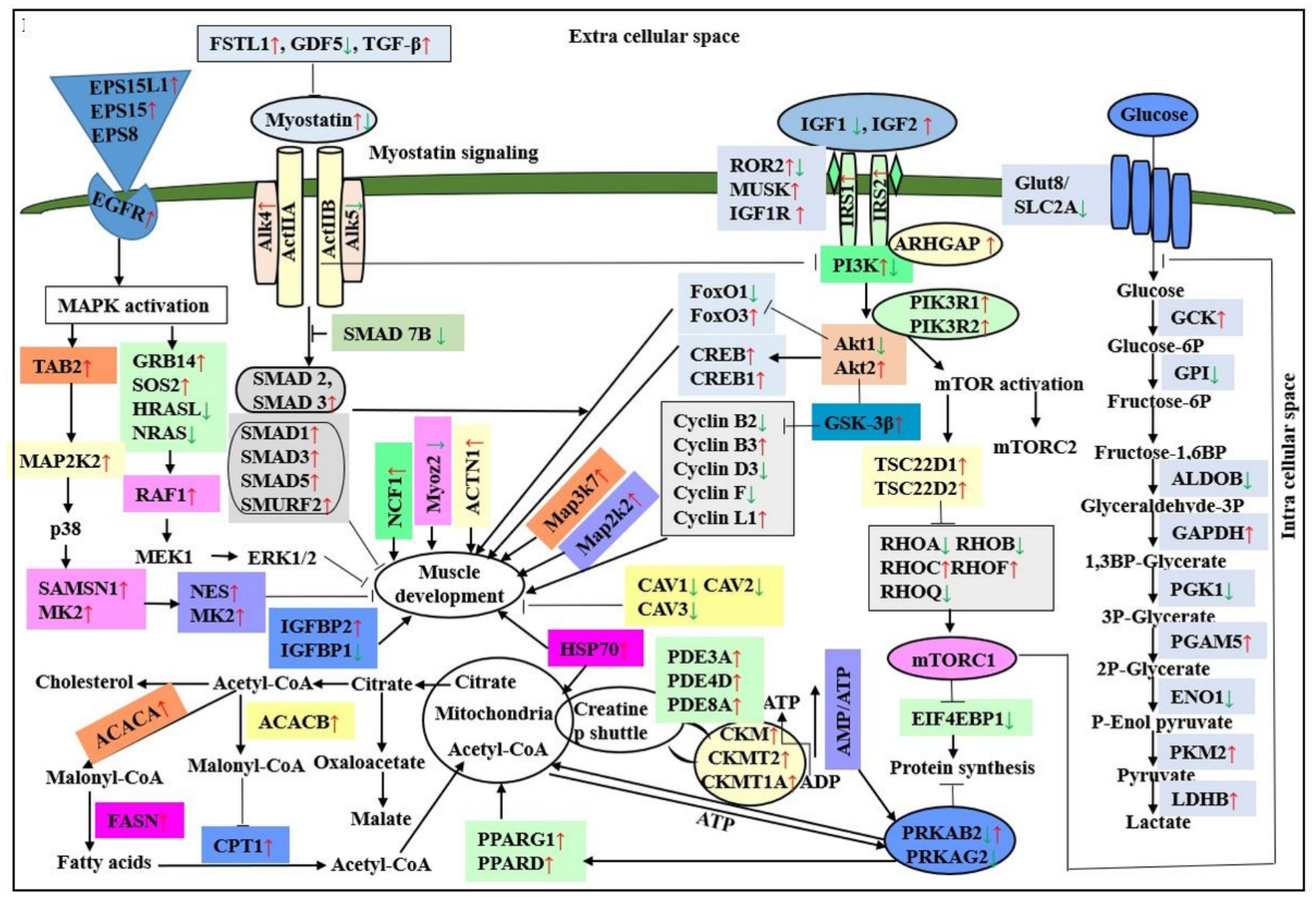

Figure 8

Diagrammatic representation of DEGs analysis in the 7th-day embryo and 18th-day thigh muscle of aseel as compared to respective controls of control broiler. The red and green arrows represents the up and down-regulated genes $(P<0.05)$, respectively. $\rightarrow$ the activation of the process, - inhibition of the process. 1 . Canonical pathway of Smad activation. Myostatin binds to ActRIIB and induces its assembly with activin type I receptor, subsequent phosphorylation of Smad2/3 leads to its binding with Smad4 and translocation of the complex to the nucleus where it blocks the transcription of genes responsible for the myogenesis. Smad6 and Smad7 compete for the binding with activin type I receptor and Smad7 can also prevent the formation of the Smad 2/3 and Smad 4 complex. 2. MAPK activation. The activation of MAPKs is mediated via myostatin using different pathways: TAK-1/MAPKK for p38 MAPK or Ras/Raf/MEK1 for ERK1/2. It leads to the blockade of genes responsible for myogenesis. 3. Inhibition of Akt signaling. Akt phosphorylation occurs in the response to insulin and IGF-1. In normal case, active Akt induces mTOR signal leading to the protein synthesis and at the same time, it inhibits FoxO by phosphorylation. In the pathological conditions, dephosphorylated Akt does not inhibit FoxO. It leads to the accumulation of FoxO in the nucleus where it binds to the DNA and induces the transcription of E3 ubiquitin ligases MURF-1 and Atrogin-1. Smad3 and Smad4 possibly participate in FoxO signalling.

\section{Supplementary Files}

This is a list of supplementary files associated with this preprint. Click to download.

- Tables1.docx

- SupportingDocument1Listofdifferentiallpathwaysduringembryodevelopmentstages7thdayembryoand18thdaythighmuscleascomparedtotheirrespectiveco

- SupportingDocument2SelectedcandidatereferencegenesandprimersusedforqPCRanalysis..xIsx 